\title{
Dendritic Growth and Remodeling of Cat Retinal Ganglion Cells During Fetal and Postnatal Development
}

\author{
A.S. Ramoa, ${ }^{a}$ G. Campbell, and C.J. Shatz \\ Department of Neurobiology, Stanford University School of Medicine, Stanford, California 94305
}

We have studied the development of retinal ganglion cell morphology in the cat's visual system trom early fetal to postnatal times. In particular, we have examined the contribution of growth and remodeling to the establishment of mature retinal ganglion cell form. Ganglion cells were identified by retrograde labeling with rhodamine latex microspheres deposited in the superior colliculus and lateral geniculate nucleus between embryonic day 34 (E34; birth = E65) and adulthood. To reveal the fine morphological details of retrogradely labeled ganglion cells, $48 \mathrm{hr}$ later Lucifer yellow was injected intracellularly in living retinae that had been dissected and maintained in vitro.

Our results show that at E35-37 the majority of ganglion cells are very simple in morphology, with a few dendritic processes that are generally aligned in a radial direction towards or away from the optic disc. During the ensuing 2 week period, there is a progressive growth and elaboration of dendrites. By E50, some ganglion cells resembling the adult alpha, beta, and gamma classes can be identified based on comparisons of the appearance and dimensions of their dendritic trees and somata with neighboring filled cells. However, ganglion cell dendrites and axons at this age express several transient morphological features. The axons of ganglion cells give rise to delicate processes originating from the intraretinal portion of the axon, including side branches, present in about half of the cells, and occasionally bifurcations that give rise to axon collaterals. These transient axonal features are present throughout development, including the neonatal period; no axon collaterals were observed after postnatal day 15, while axonal side branches persisted even at P31 but were gone by adulthood. Ganglion cell dendrites exhibit excessive branches and exuberant somatic and dendritic spines. Quantitative analysis of these processes shows that after E45 dendritic trees increase dramatically in complexity, reaching the peak number of spines and branch points by the first week of postnatal life. The number of dendritic processes then falls abruptly to reach

Received Oct. 6, 1987; revised Jan. 21, 1988; accepted Jan. 22, 1988

We thank Drs. L. C. Katz and M. Konishi for their generous assistance in establishing the intracellular injection techniques, Drs. E. Friauf and S. McConnell for their helpful criticisms of the manuscript, J. J. M. Chun and M. W. Siegel for help with the fetal surgeries, Sonia Friedman for help with the histology and quantitation, and Cecele Thomas for assistance with word processing. Supported by grants from the National Institutes of Health (EY 02858), the National Science Foundation (BNS 8616798), and the March of Dimes.

Correspondence should be addressed to Drs. Ramoa and Shatz at the above address.

a Present address: Laboratorio de Farmacologia Molecular II, Instituto de Biofisica da UFRJ Cidade Universitaria, Rio de Janeiro, 21941 Brazil.

Copyright (C) 1988 Society for Neuroscience $0270-6474 / 88 / 114239-23 \$ 02.00 / 0$ near-adult levels by the end of the first postnatal month. Even though dendritic morphology closely resembles that seen in the adult at this age, ganglion cell bodies and dendrites must continue to grow to reach their adult size.

Our results provide quantitative evidence that, although the basic form of retinal ganglion cells is laid down as early as 2 weeks before birth, the adult morphology is acquired by a combination of progressive growth and extensive remodeling. In addition, the presence of exuberant axonal and dendritic processes during development suggests that there is a transient network of synaptic connectivity that may play a role in the establishment of adult ganglion cell form and function.

Retinal ganglion cells in the adult mammalian visual system display a remarkable diversity of morphology and function. In the cat's retina at least 5 ganglion cell classes can be identified based on dendritic branching, soma size, and the pattern of central projections (Boycott and Wässle, 1974; Rodieck, 1979; Kolb et al., 1981; Wässle, 1982; Leventhal et al., 1985). Of these, 2 of the classes, the alpha and beta cells, are not only morphologically well defined, but also have characteristic visual response properties that make them functionally distinct (Peichl and Wässle, 1981; Saito, 1983; Fukuda et al., 1984). The alpha cells have the largest somata of any class and have a very large dendritic tree, while the beta cells have somata in the medium range, with small, highly branched dendrites. In contrast, some of the other classes such as gamma cells are functionally heterogeneous but share in common the morphological properties of a small soma and sparsely branched, long radiating dendrites (Boycott and Wässle, 1974; Fukuda et al., 1984; Stanford, 1987; for reviews, see Rodieck and Brening, 1983; Sherman, 1985).

In view of this variety of form and function, the question arises as to when and how retinal ganglion cells achieve their mature characteristics during development. In the cat, a good deal is known about the development and maturation of the central projections of retinal ganglion cells from early fetal ages. Ganglion cell axons arrive at their central target nuclei, the lateral geniculate nucleus (LGN) and the superior colliculus (SC), about midway through the $65 \mathrm{~d}$ gestation period (Williams and Chalupa, 1982; Shatz, 1983). In the ensuing week or so, axons from the 2 eyes grow into their targets, where they are initially intermixed. Then, hetween embryonic day 45 (E45) and birth, the characteristic eye-specific layers of the LGN and the restricted patches of eye input in the SC emerge as ganglion cell axons from the 2 eyes segregate from each other (Williams and Chalupa 1982; Shatz, 1983). During this period, individual retinogeniculate axons undergo a stereotyped sequence of morphological changes in which initially very simple axons tipped 
with growth cones acquire, by birth, complex teminal arbors located in LGN territory appropriate to their eye of origin (Sretavan and Shatz, 1986). However, even at birth the terminal arbors of retinogeniculate axons belonging to alpha and beta ganglion cells are morphologically similar, and it is not until many weeks postnatally that they can be distinguished from each other using a combination of functional and morphological criteria (Rusoff and Dubin, 1977, 1978; Sur et al., 1984; Friedlander et al., 1985; for review, see Shatz and Stretavan, 1986).

Much less is known about the intrarctinal events associated with the maturation of ganglion cells, despite the fact that this knowledge is essential for an understanding of how retinal ganglion cells achieve their adult properties. ${ }^{3} \mathrm{H}$-thymidine studies in the cat have indicated that ganglion cells are generated at the germinal zone early in gestation, between E21 and E31 (Kliot and Shatz, 1982; Walsh et al., 1983; Walsh and Polley, 1985). Ganglion cell number reaches a maximum by about E40, after which about $70 \%$ are eliminated by cell death during prenatal life to achieve nearly adult levels by birth (Williams et al., 1986). Ultrastructural studies have shown that synaptogenesis within the inner plexiform layer begins during this period of cell death and is complete by about 3 weeks after birth (Morrison, 1982; Maslim and Stone, 1986). As regards the morphological development of ganglion cells, however, most information concerns the postnatal period. By early postnatal life, alpha and beta cells can be distinguished from each other based on their morphological appearance (Rusoff and Dubin, 1978; Dann et al., 1987), and this appears to be the case as early as E52, based on a recent descriptive study by Maslim et al. (1986).

Here, we have confirmed and extended these previous observations by studying the morphological development of identified retinal ganglion cells between E35 and adulthood in the cat. To solve the problem of distinguishing ganglion cells from other cell types during development, ganglion cells were marked by the retrograde transport of rhodamine-labeled microspheres injected into retinorecipient targets. To reveal the fine morphological details of ganglion cells during development, intracellular injections of Lucifer yellow were made in living retinal whole mounts maintained in vitro according to the methods of Katz et al. (1984). This approach has enabled us to determine not only when the basic form characteristic of different ganglion cell classes appears, but also how it is acquired. For instance, we were interested to know whether extensive remodeling of dendrites occurs during development in view of the fact that ganglion cell dendrites can remodel postnatally in response to experimental perturbations (Perry and Linden, 1982; Eysel et al., 1985). On the other hand, Maslim et al. (1986) suggested that dendritic growth without remodeling can account for the final adult morphology. Our preliminary results suggested that remodeling is involved in dendritic development (Ramoa et al., 1987), and here we present further quantitative evidence in favor of the alternative that mature ganglion cell form is achieved by a combination of growth and remodeling.

\section{Materials and Methods}

This study is based on a total of 472 retinal ganglion cells that were intracellularly injected with Lucifer yellow (LY). The retinae of $14 \mathrm{fe}-$ tuses of known gestational ages between E35 and 63 and 11 cats between postnatal day $3(\mathrm{P} 3)$ and adult were examined. Table 1 shows the ages of the animals and the number of ganglion cells studied. To obtain timed pregnancies, adult female cats in estrus (Scott, 1970) were placed with a male for $24 \mathrm{hr}$ and the time of mating was considered as E1.
Gestation is $65 \mathrm{~d}$, and the day of birth is considered as P0 (=E65). This method allows one to time pregnancies to within plus or minus $1 \mathrm{~d}$ of uncertainty (see Shatz, 1983, for more detail).

Surgery and injection of latex microspheres. Pregnant cats received a subcutaneous injection of atrophine sulfate $(0.05 \mathrm{mg} / \mathrm{kg})$ followed by an intramuscular injection of ketamine hydrochloride $(20 \mathrm{mg} / \mathrm{kg})$ and acepromazine $(0.2 \mathrm{mg} / \mathrm{kg})$. Next, an endotracheal tube was inserted, and anesthesia was maintained with a combination of halothane $(0.5-1.5 \%)$ and oxygen for the duration of the surgery. An arm vein was cannulated to allow the continuous infusion of lactated Ringer's solution during surgery and occasional injections of terbutaline sulfate (Brethine, 0.03 $\mathrm{mg} / \mathrm{kg}$ ) to reduce uterine contraction. Heart rate and expired $\mathrm{CO}_{2}$ were monitored routinely.

The method of fetal surgery in the cat has been described before (Shatz, 1983), and only a brief description will be provided here. To expose the 2 uterine horns, the skin and abdominal musculature were incised along the midline. Next the uterus and fetal membranes were opened, taking care not to incise the placenta. This procedure allows the partial exposure of the fetus for the intracerebral injections of an undiluted suspension of fluorescent rhodamine latex microspheres (Katz et al., 1984; Tracer Technology). Using a Unimetrics syringe ( $1 \mu \mathrm{l})$, penetrations were made through the skull, and several injections of a $0.1-0.2$ $\mu \mathrm{l}$ volume of this suspension were made into the region of the lateral geniculate nucleus (LGN) and superior colliculus (SC). The fetal cranium is very soft and usually offers little resistance to the penetration of the needle. In case of any resistance, a small puncture in the skull was made with a number 11 blade or a $27 \mathrm{G}$ needle to allow for easy penetration of the needle. To assure that both LGN and SC were injected, we made multiple injections (spaced about $1 \mathrm{~mm}$ ) along the needle track. After the injections, the fetal head was replaced inside the uterus, and the uterine walls (including the fetal membranes), abdominal muscle, and skin were sutured closed. Anesthesia was then discontinued, and a few minutes later the mother cat was revived and placed in "intensive care" until recovery was complete.

Injection of latex microspheres in postnatal animals involved the use of standard stereotaxic techniques. First, animals were given subcutaneous injections of atropine sulphate $(0.05 \mathrm{mg} / \mathrm{kg})$ and then anesthetized with a combination of halothane $(0.5$ to $2 \%$ ) and oxygen for the duration of the surgery. The animals were placed in a stereotaxic apparatus, the skin overlying the head was incised, and 2 holes were drilled, centered on the stereotaxic coordinates for the LGN and SC. At each of these holes, a Unimetrics syringe $(1 \mu \mathrm{l})$ was used to make multiple injections $(0.2 \mu \mathrm{l})$ of the suspension of rhodamine-labeled latex microspheres. The injections were regularly spaced in a grid pattern with a separation of approximately $500 \mu \mathrm{m}$ between penetrations. To assure that both the LGN and SC were labeled, in each penetration we made several injections approximately $1 \mathrm{~mm}$ apart. Finally, the skin was sutured closed, and the cat was revived and returned to the colony. Sterile surgical technique was employed throughout these procedures in both pre- and postnatal animals.

Retinal preparation. After a period of $48 \mathrm{hr}$ to allow for retrograde axoplasmic transport of the rhodamine-labeled latex microspheres, fetal animals were anesthetized with halothane via the maternal circulation following the procedures described above, then removed by cesarian section and placed on ice for removal of the retinae. Postnatal cats were anesthetized with Nembutal (intraperitoneal, $30 \mathrm{mg} / \mathrm{kg}$ ), again after a $48 \mathrm{hr}$ postinjection survival and, following eye removal, euthanized with an overdose of Nembutal. The following procedures for retinal dissection were similar for both fetal and postnatal animals. First, a small mark in the upper sclera was made with a hot needle to preserve information about retinal orientation. Eyes were removed, placed in a petri dish with cold, oxygenated Ringer's solution (Shatz and Kirkwood, 1984), and a long incision was made that extended from the scar left by the hot needle up to the optic disc. A circumferential incision was made at the border between the ciliary margin, and the retina and the anterior portion of the eye were removed. Retinae were then gently dissected free from the pigment epithelium and lens with the use of a fine paint brush. Individual retinae or retinal pieces were whole-mounted onto strips of embedding bag paper (Spectrum), and one retina was placed in a tissue-slice chamber mounted on the stage of a Zeiss WL compound microscope modified for the in vitro experiments and equipped for fluorescence. A $32 \times$ long-working-distance objective (Leitz UTK50, N.A. 0.4) that fitted through a hole in the chamber's removable cover allowed for observation of the slice preparation. Oxygenated Ringer's solution maintained at room temperature flowed continuously $(30 \mathrm{ml} /$ 
$\mathrm{hr}$ for the youngest fetuses, up to $100 \mathrm{ml} / \mathrm{hr}$ for the adults) through this chamber. Additional oxygenation was provided by a humidified mixture of $95 \% \mathrm{O}_{2}: 5 \% \mathrm{CO}_{2}$ inside the chamber. The extra retinae were temporarily placed in a storage chamber kept at $33^{\circ} \mathrm{C}$ and with oxygenated Ringer's solution flowing at approximately $60-80 \mathrm{ml} / \mathrm{hr}$. Slices kept in both chambers remained viable, as evaluated by recording of membrane potentials, for up to $8-10 \mathrm{hr}$.

Intracellular recording and labeling. To label retinal ganglion cells with LY, we introduced small modifications into the procedures described by Katz (1987) to fill cortical cells. Glass electrodes were made from Omega dot tubing (1.2 mm O.D. and $0.6 \mathrm{~mm}$ I.D., Frederick Haer Co.) using a Brown-Flaming micropipette puller (Sutter Instruments). Next, electrode tips were bent (Hudspeth and Corey, 1978) to allow for approximately vertical penetrations into the retina. Electrodes were filled with a $20 \% \mathrm{LY}-\mathrm{CH}$ (Sigma) solution in $0.1 \mathrm{~m} \mathrm{LiCl}$ (Stewart, 1978) and placed in sealed and humidified glass containers kept in the refrigerator. Their resistance was generally around 80-100 $\Omega$.

For the intracellular injections of LY, one of the rhodamine-labeled cells was selected (using Zeiss rhodamine filter set 4877 14) and positioned near the center of an eyepiece graticule. The electrode tip was viewed in LY fluorescence (Zeiss filter set 487709 ) to place it near the center of the graticule and was advanced vertically through the retina using a Huxley micromanipulator. Standard electronics were used to monitor the potential changes as the electrode advanced into the cell body. Impalement was generally accompanied by a drop in potential of up to $-60 \mathrm{mV}$, after which cells were injected with LY using rectangular current pulses ( $4 \mathrm{~Hz}, 200 \mathrm{msec}, 2-10 \mathrm{nA}$, electrode negative). The time necessary for reliable injection of ganglion cells varied with age. Thus, for the small cells present in fetal animals, a few seconds were sometimes sufficient to reveal the full extent of the dendritic tree. In contrast, up to several minutes were required to fill completely adult retinal ganglion cells.

Tissue processing and data analysis. After several retinal ganglion cells had been injected with LY, the retina was removed from the chamber and fixed by immersion in $4 \%$ paraformaldehyde in $0.1 \mathrm{M}$ phosphate buffer. One day later the retina was whole-mounted onto gelatinized slides ( 2 coats of $5 \%$ gelatin) (Wässle et al., 1975; Stone, 1981). The retina was firmly attached to the gelatinized slide vitreal side up by sandwiching it, after blotting dry, between the gelatinized slide and 2 pieces of embedding bag paper (as used in the chamber), followed by one piece of bibulous paper (VWR), all soaked in 4\% paraformaldehyde, and finally covered on top by an uncoated slide. This sandwich was weighted with a small brass block and immersed in the same fixative for 1-3 d. If rhodamine-labeled microspheres were not used in the experiment, the retina was then simply rinsed in distilled water, dehydrated in a graded series of ethanols, cleared in xylene (for about $1 \mathrm{~min}$ each), and then mounted under a coverslip with Krystalon (Harleco). Microsphere-labeled retinae were rinsed briefly in distilled water and air-dried for 2-8 hr depending on the age. When judged to be sufficiently dry and not excessively cracked, the retinae were very rapidly dehydrated in 100\% ethanol (for $10 \mathrm{sec}$ ), cleared in xylene (for $10 \mathrm{sec}$ ), and mounted under a coverslip with Krystalon. The cells were then photographed at several magnifications (Kodak ASA 400, Ektachrome film) with rhodamine and LY filters (see above) and drawn with a $63 \times$ oilimmersion objective (N.A. 1.25) using a camera lucida attachment. Drawings were made with white ink on black paper (L. Katz, personal communication). This contrast allowed for better visualization of the LY-filled processes while drawing. The final magnification of the drawings was approximately $1000 \times$.

The camera lucida drawings allowed us to measure dendritic and cell body diameter and to count the number of spines and dendritic branch points. A process was considered a spine if it was less than or equal to $5 \mu \mathrm{m}$ in length. A branch point was defined as a point of bifurcation giving rise to processes that further bifurcate or are longer than $5 \mu \mathrm{m}$. The $5 \mu \mathrm{m}$ limit was selected because an analysis of dendritic segment length revealed that, for both the alpha and gamma cells illustrated in Figure $9, C$ and $E$ (age P3), the distribution of segments as a function of length is unimodal and peaks at $2 \mu \mathrm{m}$. Thus, the $5 \mu \mathrm{m}$ limit assures that the majority of short processes considered to be spines are grouped together. All ganglion cells filled with LY were included in these analyses.

Eccentricities of all cells were obtained by mcasuring the distance from the labeled cell to the estimated area centralis on camera lucida drawings of the retinal whole mounts (see Fig. 3). The area centralis was estimated using the data of Rapaport and Stone $(1982,1983)$ and Robinson (1987).
Table 1. Summary of ganglion cells injected at each age studied

\begin{tabular}{lll}
$\begin{array}{l}\text { Age at } \text { in vitro } \\
\text { experiment }\end{array}$ & $\begin{array}{l}\text { Microsphere } \\
\text { injection }^{a}\end{array}$ & $\begin{array}{l}\text { No. of cells } \\
\text { successfully } \\
\text { injected and } \\
\text { analyzcd }^{b}\end{array}$ \\
\hline E35 & - & 39 \\
E36 & + & 22 \\
E37 & + & 58 \\
E45 & - & 18 \\
E50 & + & 11 \\
E52 & - & 17 \\
E57 & + & 22 \\
E62 & - & 30 \\
E63 & + & 53 \\
P3 & + & 25 \\
P7 & + & 13 \\
P8 & + & 60 \\
P15 & - & 16 \\
P31 & + & 34 \\
P32 & + & 34 \\
Adult & + & 20 \\
\hline
\end{tabular}

a Rhodamine microspheres were injected into LGN and superior colliculus in vivo $48 \mathrm{hr}$ prior to the in vitro experiment.

${ }^{b}$ A cell was considered successfully injected if the dendrites were well filled and not beaded, and if the injection did not result in excessive extracellular leakage of label. Cells were analyzed by photography, camera lucida drawings, and/or by counting processes (side branches, etc.)

After eye removal, animals were perfused intracardially with a $0.1 \mathrm{M}$ phosphate buffer, followed by $4 \%$ paraformaldehyde in 0.1 phosphate buffer. For verification of injection sites, the brain was sectioned at 100 $\mu \mathrm{m}$ in a vibratome (Lancer), and the sections were mounted on gelatinsubbed slides. Every third or fourth section was stained with cresyl violet. The other sections were air-dried, dehydrated in $100 \%$ ethanol for $10 \mathrm{sec}$, cleared in xylene for $10 \mathrm{sec}$, and coverslipped with Krystalon. Results showed that, in each animal in which rhodamine-labeled retinal ganglion cells were present, the SC and/or LGN and, occasionally the optic tract, had been injected successfully with the suspension of rhodamine-labeled microspheres.

\section{Results}

Our findings are divided into 3 subsections. In part I we describe how we have used the techniques of intracellular dye injection and retrograde labeling to examine the morphological development of retinal ganglion cells. Next, in part II, we present evidence suggesting that some of the adult classes of retinal ganglion cells can be identified before birth. Finally, in part III, we show that ganglion cells in fetal and neonatal development exhibit several morphological features that are not present in the adult.

\section{Application of double-labeling technique to the study of fetal retina}

Intracellular injections of LY into living retinal ganglion cells maintained in vitro reveal their axons and fine morphological details of their dendritic trees. For example, Figure $1 A$ shows a LY-filled cell at P31 that was located approximately $5.5 \mathrm{~mm}$ from the area centralis. In morphology this cell is typical of the adult beta class at this eccentricity (it has a medium-sized soma and small, highly branched dendritic tree). As shown in the same photograph, surrounding ganglion cells are filled with rhodamine-labeled microspheres that had been injected into the SC 

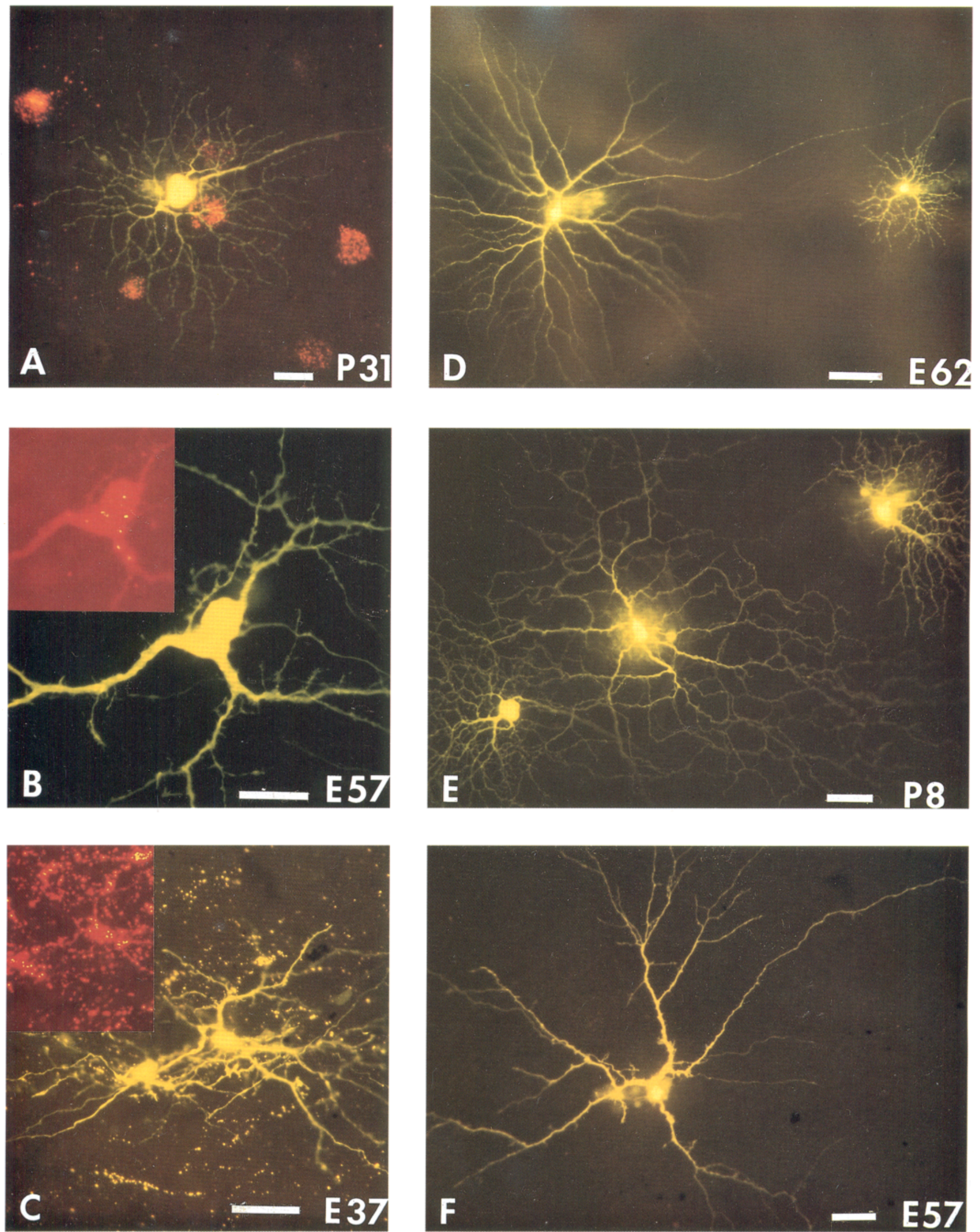

Figure 1. Color micrographs of retinal ganglion cells intracellularly filled with Lucifer yellow (LY) in vitro in preparations of living fetal ( $B-D, F)$ and postnatal $(A, E)$ cat retinae. This figure shows the merits of this technique in revealing the axon and fine details of the dendritic tree. $A-C$ 


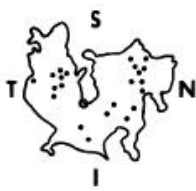

E50

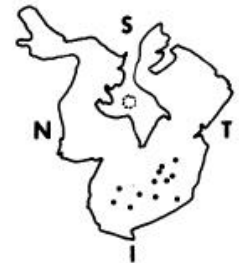

P3

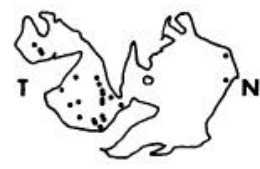

E57
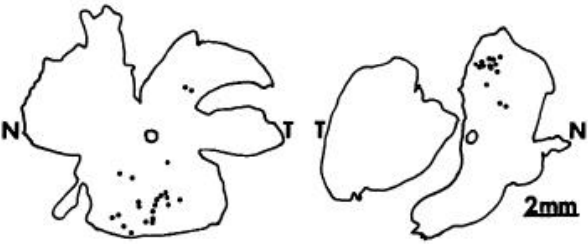

P31

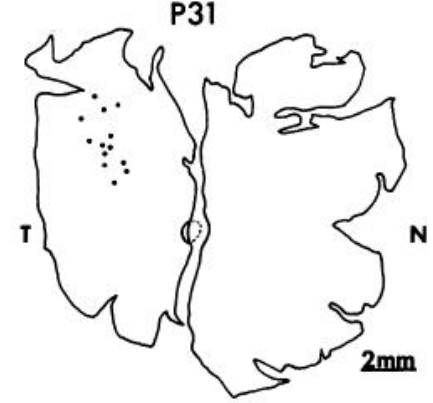

Figure 2. Camera lucida drawings of retinal whole mounts at E35P31 illustrating the positions of LY-injected ganglion cells analyzed (dots) in some of the experiments. In order to compare the morphology of nearby ganglion cells, injections were usually made into clusters of cells at a similar eccentricity. Note that ganglion cell clusters are in the peripheral half of most retinae. The position of the optic disc is shown as an unfilled irregular circle that is dashed when its position had to be estimated from the trajectories of labeled ganglion cell axons. The retinae are drawn in fragments because they were usually studied one half at a time and subsequent histological processing designed to preserve the microspheres often caused further fragmentation of this very fragile immature tissue. The superior $(S)$, inferior $(I)$, temporal $(T)$, and nasal $(N)$ quadrants are labeled, except for E45, where the orientation was lost during the dissection.

and LGN 2 d previously. (In this double-exposure, the microspheres in the LY-injected cell cannot be seen.) The same technique can be applied to fetal retinae, as illustrated in Figure 1, $B$ and $C$. Figure $1 B$ shows a LY-filled cell at E57, a week before birth. Reconstruction indicated that the cell was located in the inferior retina about $3 \mathrm{~mm}$ from the area centralis (see Fig.
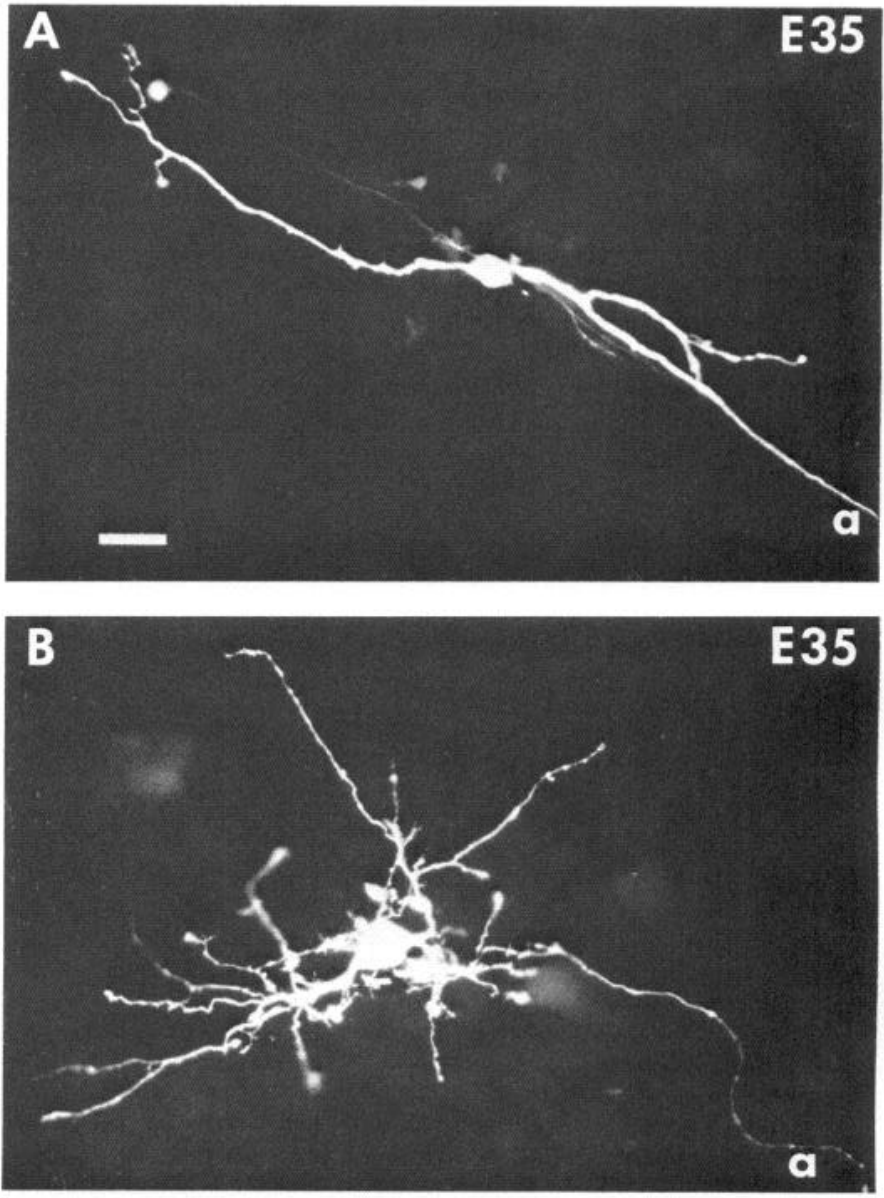

Figure 3. Examples of LY-injected ganglion cells at E35, the youngest age studied. $A$ illustrates the very simple morphology of most ganglion cells at this age, while $B$ shows that some cells with complex dendritic trees are already present. Note also that many dendrites are tipped with growth cones and in $A$ the dendrites are aligned parallel to the axon $(a)$ trajectory. Axons of both cells could be followed towards the optic disc. Cell $A$ is located in superior, nasal peripheral retina; cell $B$ is in inferior, nasal peripheral retina. Scale bar, $10 \mu \mathrm{m}$.

2: E57). The inset, a photo of the same cell taken with rhodamine epifluorescence optics, shows that the cell contains several retrogradely transported microspheres scattered within the soma and proximal dendrites. Similarly, Figure $1 C$ shows a pair of LY-filled cells at E37, one of the youngest ages studied, that were also labeled with microspheres, as indicated in the inset.

illustrate the double-labeling method used. Retinal ganglion cells were first identified by the retrograde transport of rhodamine-labeled latex microspheres (red) injected into retinorecipient nuclei in vivo $24-48 \mathrm{hr}$ before they were filled with LY in vitro. A, Beta cell at P31 double-labeled with LY and rhodamine microspheres surrounded by other rhodamine microsphere-labeled ganglion cells, and located in the temporal retina approximately $5.5 \mathrm{~mm}$ from the area centralis. In this double-exposure, the microspheres in the LY-filled cell cannot be seen. $B$, Double-labeled ganglion cell at E57 shown using LY-fluorescence. (Inset shows in rhodamine fluorescence of the microsphere-labeled soma.) This cell is located in the inferior retina about $3 \mathrm{~mm}$ from the area centralis and is also shown in Figure 18 (lower cell). $C$, Two double-labeled ganglion cells at E37 filled with LY from a single injection into the cell on the right. Inset shows in rhodamine-fluorescence the microsphere-labeled somata and proximal dendrites of both double-labeled cells surrounded by some microsphere-only-labeled cells. (Bright microspheres can also be seen in the main figure, where LY-fluorescence was used.) $D$ and $E$ demonstrate that nearby ganglion cells at a similar eccentricity can be injected to compare morphology. $D$, LY-filled cells at E62 resembling the adult alpha (left) and beta (right) classes. Axons can be seen arising from the right of each cell. E, Two LY-fluorescent beta cells flanking an unclassified cell at P8. All 3 cells were also labeled with rhodamine microspheres. $F$, Double-labeled gamma cell at E57 in LY-fluorescence. A drawing showing the entire cell can be seen in Ramoa et al. (1987, fig. 2, E57 class III). Note that in this and subsequent photographic figures many LY-filled somata and proximal dendrites appear larger than they are due to photographic overexposure, necessary in order to show fine axon and dendritic features. Scale bars: $A, C$, and $E, 20 \mu \mathrm{m} ; B, 10 \mu \mathrm{m} ; D, 50 \mu \mathrm{m} ; F, 30 \mu \mathrm{m}$. 

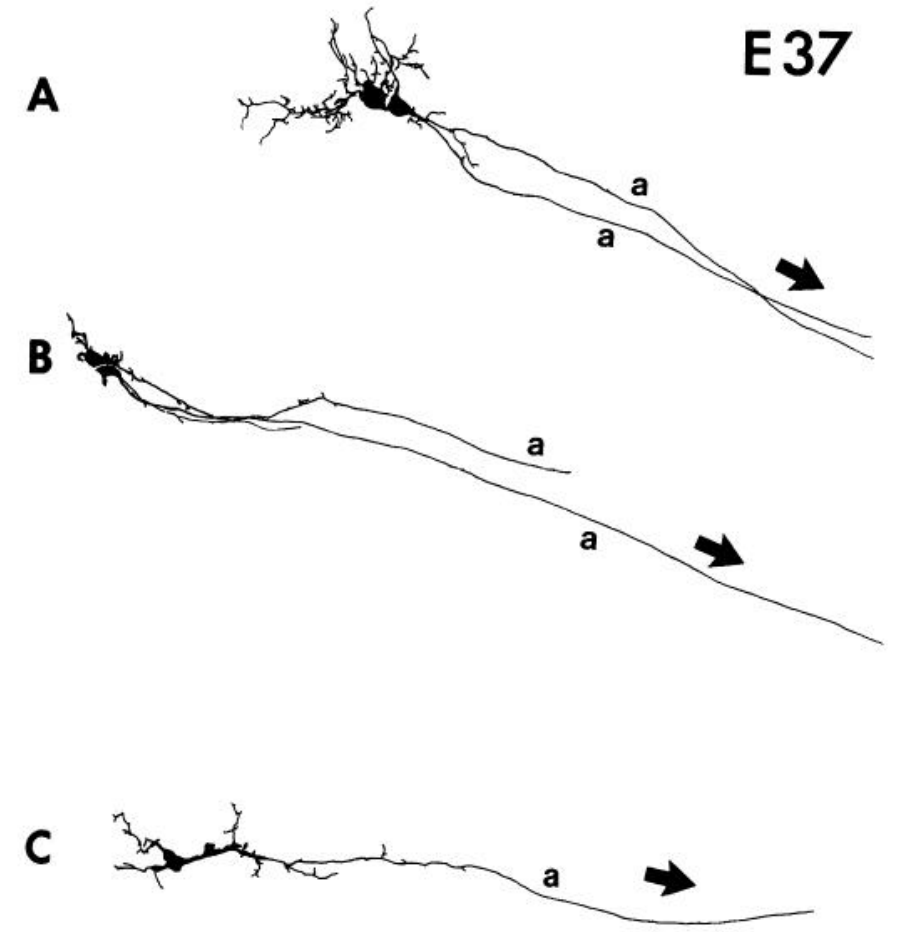

$50 \mu \mathrm{m}$

Figure 4. Camera lucida drawings of double-labeled ganglion cells at E37 with immature dendritic trees, and with axons $(a)$ running without deviation towards the optic disc (arrows). $A$ and $B$, Pairs of dye-filled cells labeled from a single LY injection. $C$, A single cell. Note the small side branches arising along the proximal portion of the axons.

Despite the fact that these cells do not resemble cells in the adult, the technique of retrograde labeling strongly suggests that they are retinal ganglion cells since at this age they have central projections. In some experiments (see Table 1), cells were injected with LY without the aid of retrograde labeling with microspheres. Nevertheless, it was possible to identify them conclusively as ganglion cells because they were morphologically similar to microsphere-labeled cells at similar ages and all had axons that traveled within the optic fiber layer towards the optic disc. These criteria permitted us to distinguish ganglion cells from amacrine cells, which even at the earliest ages studied do not have central projections (Campbell et al., 1987).

One of the main goals of this study was to determine when ganglion cells belonging to the different morphological classes can be identified and distinguished from each other during development (see part II). Since the size and shape of ganglion cells vary with eccentricity in the adult (Boycott and Wässle, 1974; Rodieck and Brening, 1983), it was essential in our developmental study as well to inject and compare nearby ganglion cells. This approach is feasible in vitro, as shown in the camera lucida drawings of retinal reconstructions in Figure 3. At almost every age studied, we also attempted to inject neighboring cells within the outer half of the retina in order to facilitate comparisons between different developmental stages. However, it should be noted that strict comparisons are not possible since central and peripheral retina grow differentially with respect to each other (Mastronarde et al., 1984; Lia et al., 1987; Robinson, 1987). Nevertheless, in view of the fact that ganglion cell neurogenesis has ceased by E35 (Kliot and Shatz, 1982; Walsh et

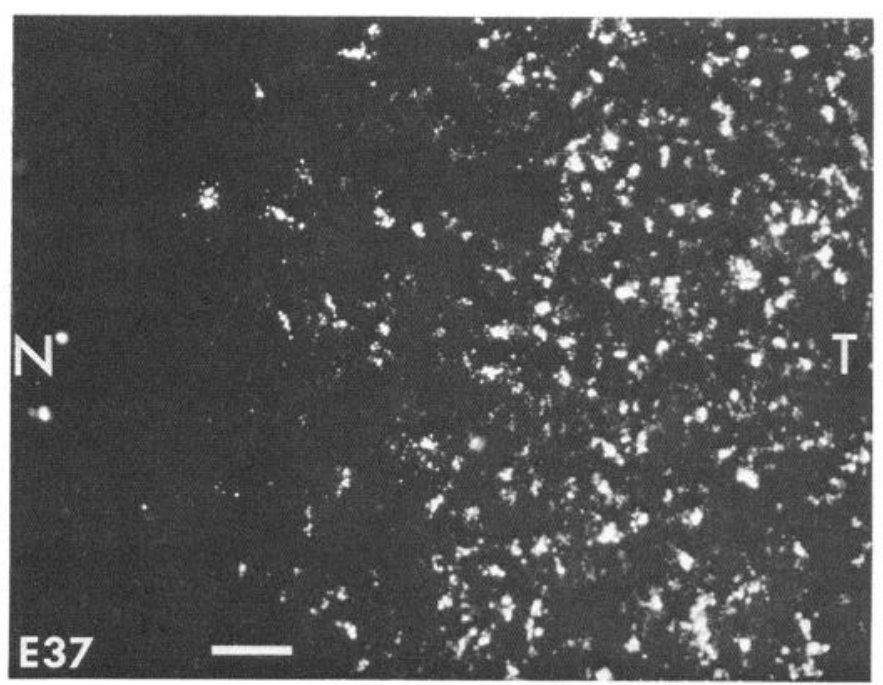

Figure 5. Low-power photograph of the retina at E37 ipsilateral to an injection of rhodamine microspheres made into retinorecipient central targets $48 \mathrm{hr}$ earlier showing microsphere-labeled ganglion cells in nasal $(N)$ and temporal $(T)$ retina. (Many are also filled with LY, which is not visible in this photograph taken with rhodamine fluorescence.) The heavy concentration of labeled cells in temporal retina indicates that a nasotemporal division of ipsilaterally projecting ganglion cells is already present at this age. Scale bar, $100 \mu \mathrm{m}$.

al., 1983; Walsh and Polley, 1985), it seems reasonable to suppose that cells located in the outer half of the retina at this early age will remain in the peripheral retina throughout subsequent development.

\section{Development of ganglion cell form}

The earliest age at which ganglion cells were studied was E35. We began our study at this age because previous work has shown that the axons of at least some ganglion cells have arrived at the LGN and SC (Williams and Chalupa, 1982; Shatz, 1983) and therefore can be retrogradely labeled. Further, ganglion cell neurogenesis, which begins at about E21 in the central retina, has ended a few days earlier (Kliot and Shatz, 1982; Walsh et al., 1983; Walsh and Polley, 1985), and many (but not all) ganglion cells have completed their migration to form the ganglion cell layer of the retina (Rapaport and Stone, 1982).

Even at E35, LY-filled cells were highly variable in morphology. For example, the 2 cells shown in the photos of Figure 3 illustrate the simplest (Fig. $3 A$ ) and the most elaborate (Fig. $3 B$ ) of the cells filled at this age. While these particular cells were not near-neighbors, it was typical to find this variability in morphology throughout the retina. The cell with simple morphology had 2 main diametrically opposed dendrites tipped with filopodia and growth cones, and an axon (Fig. 3A:a) that originated from the proximal portion of one of the dendrites and headed toward the optic disc. The other cell (Fig. $3 B$ ) had many more elaborate dendrites, some of which also ended in growth cones. Nevertheless, at this age it is not possible to recognize any of the injected cells as belonging to the adult morphological classes.

At E37 the situation is similar to that seen at E35, as illustrated in Figure 4. In addition, the figure shows another feature of ganglion cells in these young retinae. Often, in the course of injecting one cell with LY, another or several nearby cells could also be filled. Thus, a pair of cells was labeled in Figure 4, $A$ and 
$B$, and each gave rise to an axon directed towards the optic disc. Both members of each pair are retinal ganglion cells since both contained rhodamine-labeled microspheres. This point is illustrated directly in Figure $1 C$ and its inset, where 2 other cells were filled with LY although only one was injected directly and both contained microspheres. Dual filling could arise from dyecoupling via gap junctions or, alternatively, from damage. Whatever the cause, it was more common to find dye-coupled ganglion cells at these ages than later in fetal development, and by birth, dye coupling of ganglion cells was very rarely observed.

Despite the relative simplicity of LY-filled cells at E35-37, many had axons that projected to central targets since many were retrogradely labeled with the microspheres. Moreover, the distribution of retrogradely labeled ganglion cells resulting from microsphere injections in the LGN and SC of one hemisphere was surprisingly mature in that a clear nasotemporal division was present. This distribution is illustrated in Figure 5, a lowpower photograph of microsphere-labeled cells at E37 in the retina ipsilateral to the injection sites. While the temporal retina (Fig. 5, right) is filled with labeled cells, very few are present in the nasal retina, indicating that even at this early age, the majority of ipsilaterally projecting ganglion cells are located appropriately in the temporal retina. (A similar observation at E44 was made by Lia et al., 1983.) Since in the adult, almost no ipsilaterally projecting ganglion cells are located in the nasal retina (Jacobs et al., 1984), we were interested to see if the morphology of these nasally situated cells was different from that of their temporally located counterparts, at least at E37. LY injections of 6 nasally located ganglion cells revealed no obvious differences.

Another feature of ganglion cell morphology especially evident at the youngest ages studied is the tendency for the first elaborated dendrites to be aligned parallel to the trajectories of ganglion cell axons. As shown in Figure $6, A$ and $B$, photos of LY-filled cells at E35, the dendrites of the morphologically simplest ganglion cells were frequently directed radially either towards or away from the optic disc rather than circumferentially (see also Figs. $3 A ; 4, B, C$ ). The radial alignment of dendrites is clearly present on the simplest ganglion cells at E45 (Fig. 6C), and even the dendrites of some morphologically elaborate cells in fetuses as old as E50-57 show a tendency to be aligned along the radial dimension of the retina (Fig. 6D; see also Fig. 7).

Between E45 and P31, the majority of retinal ganglion cells elaborate extensive dendritic trees and assume their adult morphologies, as shown in the camera lucida drawings of Figures 7 and 8. At each age (E45, E50/52, E57, P3, P31) we have selected 5 representative LY-filled ganglion cells to illustrate the range of morphological diversity encountered. In these figures, an effort was made to illustrate cells, frequently neighbors, at similar eccentricity (within the outer half of the retina; see Fig. 2). Cells were assigned to 1 of 5 columns (A-E) based on the following criteria: Cells were assigned to column A of Figures 7 and 8 if they had small dendritic trees and medium-sized soma as determined quantitatively (see Fig. 10) and, with the exception of the cell at E45, resembled the beta class dendritic branching pattern. Cells were assigned to column B if they had large dendritic trees and large somata and (again with the exception of the cell at E45) had a dendritic branching pattern characteristic of the adult alpha class. Cells in column E had a small somata and a very large dendritic tree and, after E45, resembled the gamma class. Cells in columns C and D were intermediate in their somatic and dendritic sizes and were often difficult to
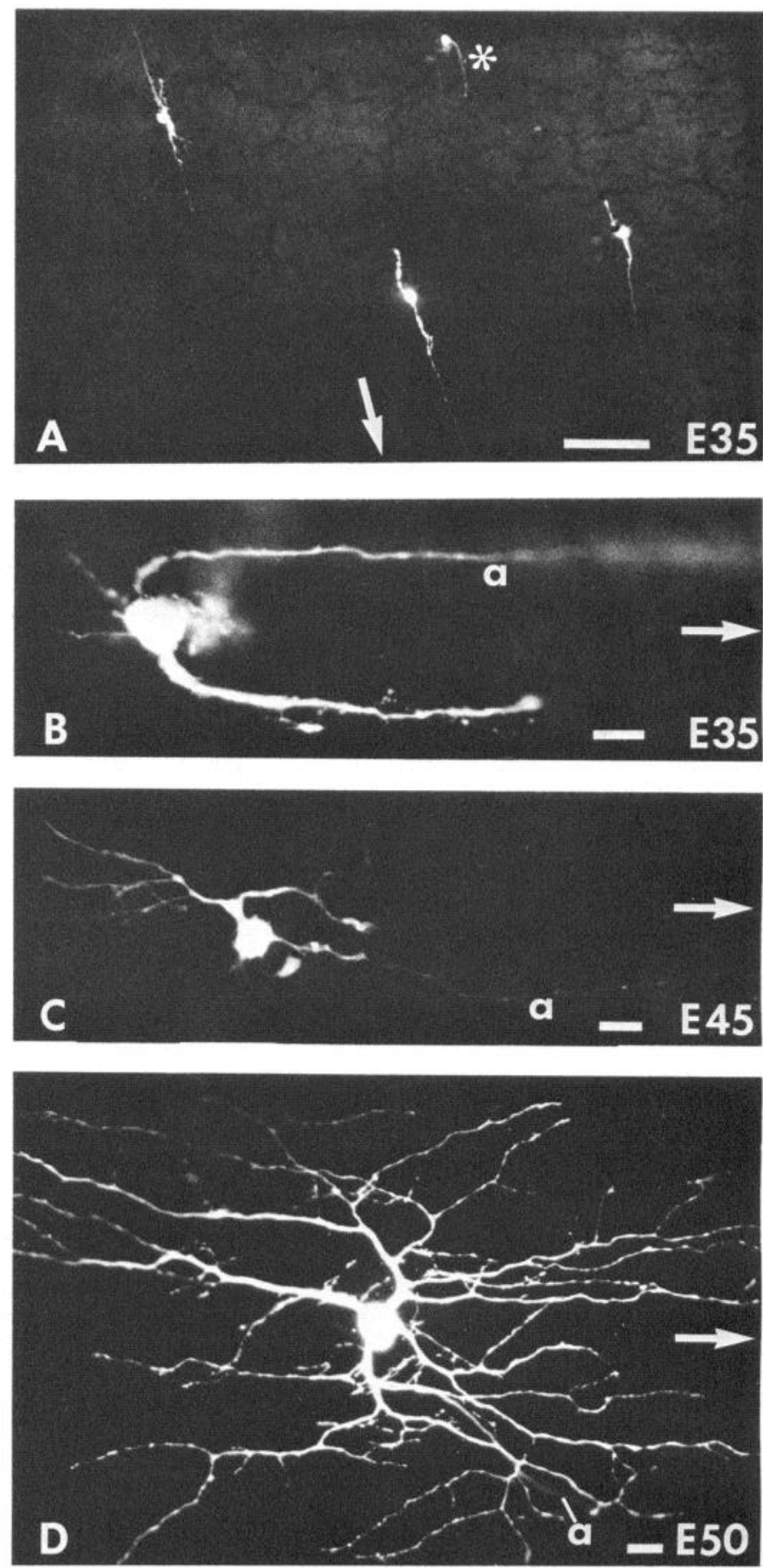

Figure 6. Examples of LY-filled ganglion cells at E35-50 illustrating the common phenomenon in young retinae that dendrites are frequently aligned parallel to the trajectories of ganglion cell axons (a). Arrows indicate direction of the optic disc. Note the fine filamentous processes on the dendrite and soma of the cell in $B$, which is a higher-power view of the cell marked with an asterisk in $A$. The cell in $D$ is double-labeled. Scale bars: $A, 100 \mu \mathrm{m} ; B-D, 10 \mu \mathrm{m}$.

classify according to the known adult classes. They are illustrated in order to convey a sense of the large morphological diversity present at each age even among neighboring ganglion cells. For example, cell $\mathrm{C}$ at P3 (Fig. 8) had one of the largest cell bodies and a large dendritic tree (see Fig. 10, P3: C)-characteristics 

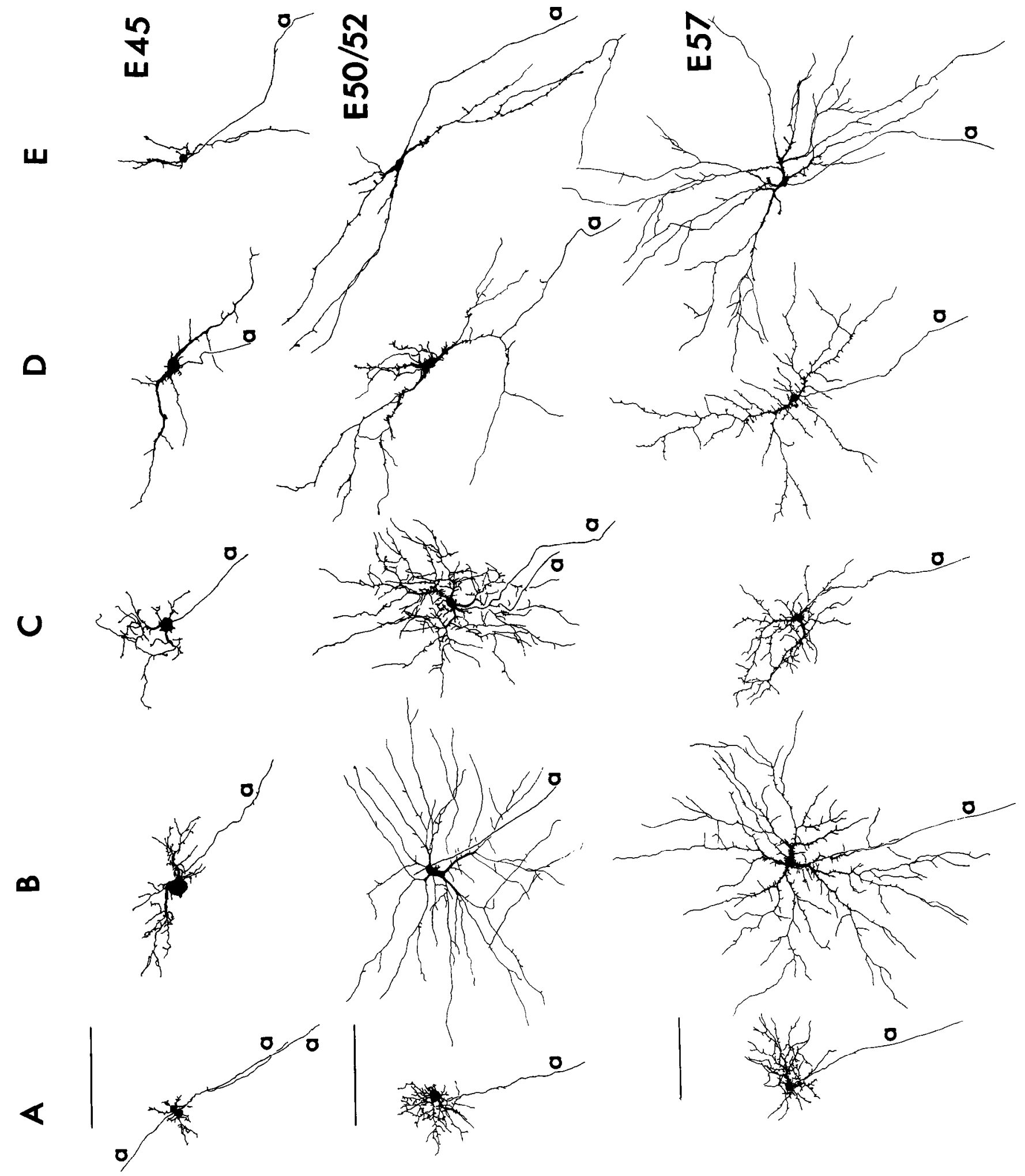


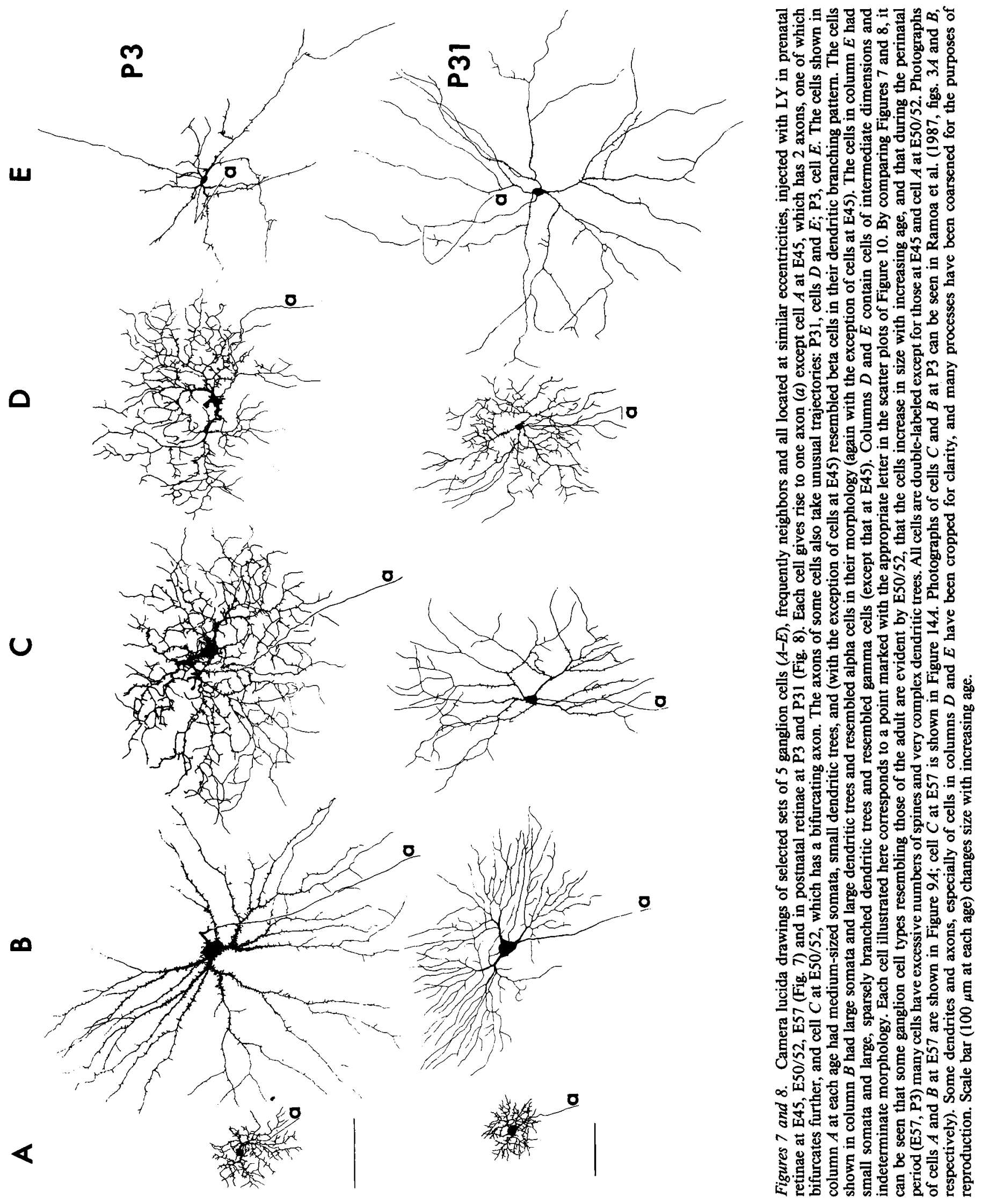



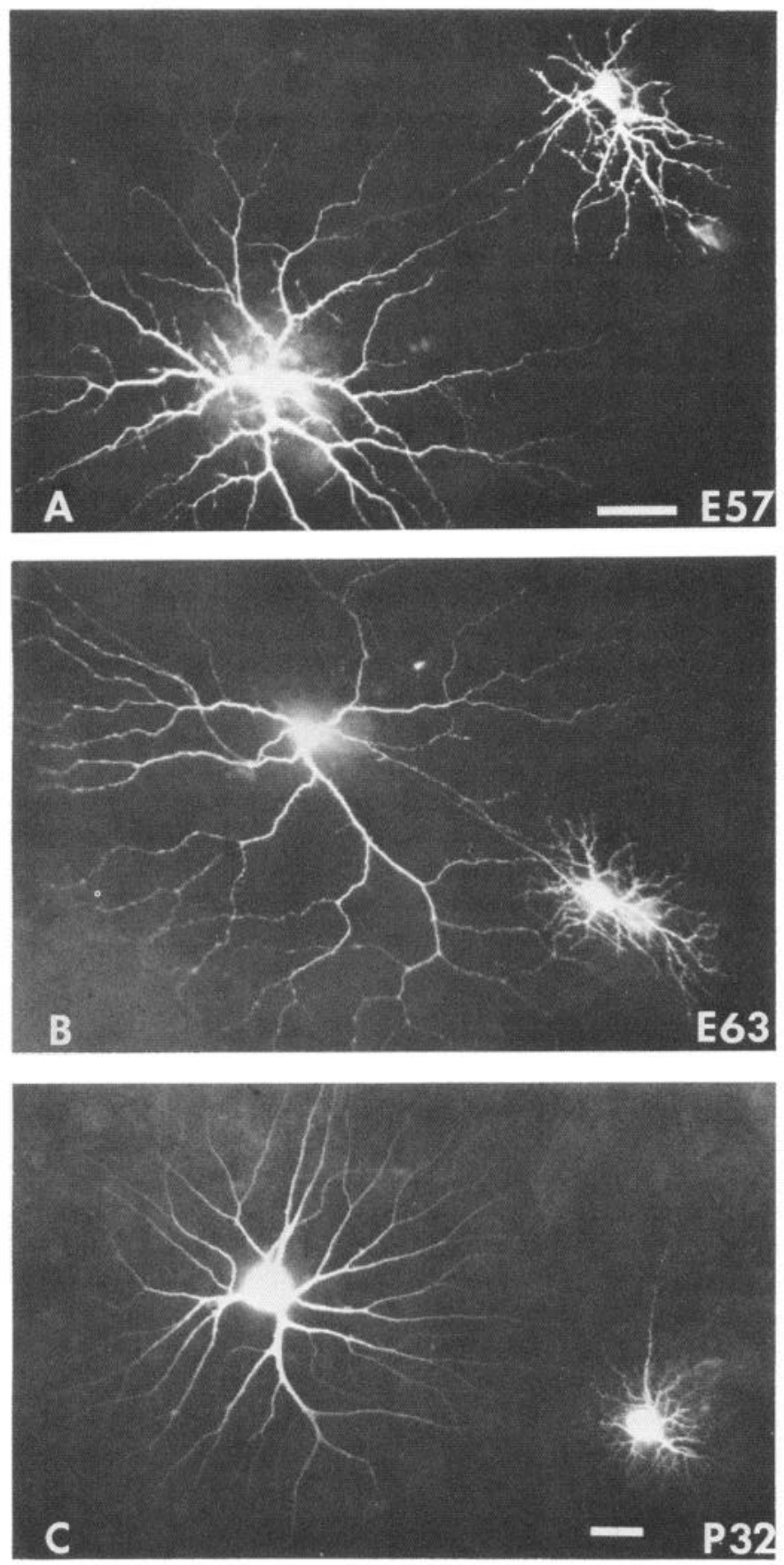

Figure 9. Pairs of double-labeled ganglion cells at E57 (A), E63 (B), and P32 $(C)$ illustrating that when neighboring cells with differing soma sizes as viewed in rhodamine fluorescence are LY-filled, they can have distinctly different morphology. The LY injections at E57 $(A)$ revealed one alpha (left) and one beta (right) cell; at E63 (B), one gamma (left) and one beta (right) cell; and at P32 (C), one alpha (left) and one beta (right) cell; and at P32 $(C)$, one alpha (left) and one beta (right). Scale bars: $40 \mu \mathrm{m}$ (bar in $A$ applies to $B$ also).

of alpha cells-yet its morphology is rather different from that of the typical alpha cell shown in Figure 8B at P3.

This approach, when applied at P31 (Fig. 8), subdivides the population of cells studied into their adult classes. For example, the cell shown in column $\mathrm{A}$ is a beta cell, that shown in column $\mathrm{B}$ is an alpha cell, while that shown in column $\mathrm{E}$ belongs to the gamma class (Boycott and Wässle, 1974). The observation that ganglion cells at P31 have reached a level of morphological maturity that permits them to be identified unambiguously as alpha, beta, or gamma is entirely consistent with the results of previous studies (Rusoff and Dubin, 1978; Rusoff, 1979; Dann et al., 1987). The identity of cells in columns $\mathrm{C}$ and $\mathrm{D}$ is not as clear cut and could correspond to other cell types less well studied in the adult (Boycott and Wässle, 1974; Leventhal et al., 1980, 1985; Brening and Rodieck, 1986; Stanford, 1987). In view of the difficulties in conclusively identifying members of these classes even in the adult, and because the alpha and beta classes are so distinctive morphologically and so well studied, we will concentrate here on the development of these classes.

Figure 7 shows that, despite the large morphological diversity present at E45, the cells cannot be recognized as belonging to any of the ganglion cell classes described at P31 or in the mature animal. In contrast, the distinctive morphology of cells in columns $\mathrm{A}$ and $\mathrm{B}$ at $\mathrm{E} 50 / 52$ is very reminiscent of the cells in columns A and B at P31, suggesting that they could correspond respectively to their alpha and beta counterparts at P31 (see Figure $8, A, B$ ). The cell illustrated in column $\mathrm{E}$ at $\mathrm{E} 50 / 52$ could also be an immature gamma cell (cf. Figs. $7 E$ and $8 E$ ) since it has a relatively small somata and extensive, sparsely branched dendrites. In contrast, the cell illustrated in column D, while in some respects resembling the cell shown in $\mathrm{E}$, has a soma that is much larger than expected for a gamma cell (see also Fig. 10, E50/52: circle marked "D”). Thus, by E50 some retinal ganglion cells begin to resemble their adult counterparts.

The distinction between cell classes becomes progressively more conspicuous at E57 and P3, when the basic morphological attributes of the alpha, beta, and gamma classes are clearly present. This distinction is evident not only in the illustrations of Figures 7 and 8 (see also Fig. $1 F$ ), but also from direct inspection of photographs of LY-filled cells between E57 and P31 that are in close proximity to each other, as shown in Figure $9 A-C$ and in color Figure $1 E$. In each case, we purposely injected nearby cells of different soma sizes (usually one large or small, and one-medium sized, soma) as viewed in rhodamine epifluorescence optics to visualize the microspheres. In Figures 9, $A$ and $C$, the $\mathrm{LY}$ injections revealed one cell with a large dendritic tree and a large cell body near a cell with a much smaller dendritic tree and a medium-sized cell body: These are characteristic features of alpha and beta classes described in the adult. In Figure $9 B$, a cell with a small cell body and large dendritic tree was injected close to a filled cell with a medium-sized cell body and small dendritic tree-characteristics of gamma and beta cells. Another example is shown in the color photograph of Figure $1 E$, where, at P8, 2 beta-like cells flanking a cell of indeterminate morphology were injected. However, it is important to note that although these observations support the conclusion that the basic structure of each cell class is laid down prenatally, ganglion cells exhibit a number of transient features including excessive dendritic branching and spines (see especially Fig. 8: P3) that will be considered in detail below in part III.

In order to obtain more quantitative information concerning the progressive growth and development of ganglion cells and to gain further insight into the emergence of ganglion cell form, an analysis of cell morphology was undertaken. At each age studied between E35 and P32, and in the 2 adults, measurements of soma size and dendritic diameter were made on each LYfilled ganglion cell. Dendritic and somatic dimensions were estimated by averaging the major and minor axes of the ellipses 


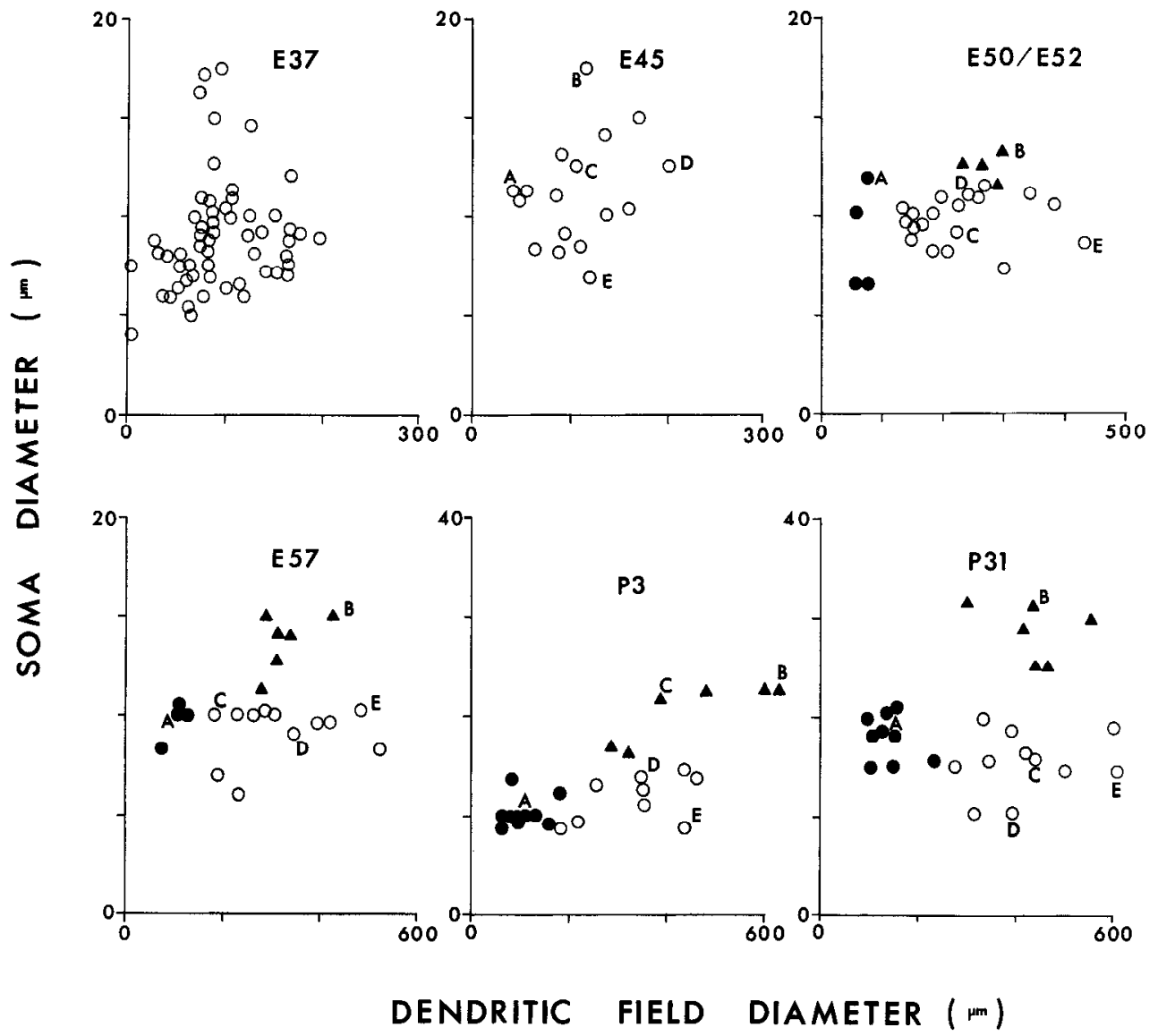

Figure 10. Scatter diagrams in which the mean soma diameters of LY-injected ganglion cells at E37, E45, E50/ 52 , E57, P3, and P31 are expressed as a function of mean dendritic field diameter (see text for details). When possible, each cell was also identified morphologically and assigned to alpha or beta ganglion cell classes according to the criteria of Boycott and Wässle (1974). At each age, filled circles indicate cells resembling beta cells; filled triangles, alpha-like cells; and open circles, unclassified cells. As expected, at P31 adultike separate clusters of cells are present. Two of these clusters represent the alpha and beta classes: Cells with the largest somata and large dendritic trees are alpha cells, and cells with medium-sized somata and the smallest dendritic trees are beta cells. Cells with a small to medium-sized soma and medium to large dendritic tree (open circles) were often harder to identify morphologically and probably include delta, epsilon, and gamma cells. Similar cell types are recognizable at all ages, except at E37 and E45; even as early as E50/ 52 the alpha- and beta-like cells tend to be clustered together, and the clustering is even more evident at E57. These scatter plots were used to select 5 cells at each age (cells $A-E$ ), except at E37, for illustration in columns $A-E$ of Figures 7 and 8 . Note scale changes at E50/ 52, E57, and P3. that circumscribe the dendritic field and the cell body. Then, at each age scatter diagrams of all the cells analyzed were constructed by plotting dendritic field diameter against soma diameter. Figure 10 shows such diagrams for 6 of the ages studied between E37 and P31. For the purposes of brevity, the diagrams for other ages have been omitted; however, the 6 ages depicted suffice to illustrate the progressive growth and development of ganglion cells.

As can be seen in Figure 10, at E37 the majority of LY-filled ganglion cells are quite small, with soma diameters of $10 \mu \mathrm{m}$ or less and dendritic diameters of about $200 \mu \mathrm{m}$ or less. By E50/ 52 a modest increase in soma size occurs in conjunction with a large increase in dendritic diameter ( $>50 \%$ of the injected cells have diameters greater than $200 \mu \mathrm{m}$ ). The injected population at E57 contains a group of cells with distinctly larger somata (>10 $\mu \mathrm{m}$ ). The soma size of this group increases still more, so that by P3 and P31 ganglion cells with soma diameters of 20 $\mu \mathrm{m}$ or greater are present, and these cells also have some of the largest dendritic field diameters $(>300 \mu \mathrm{m})$.

To analyze these results further, we took advantage of the fact that by E50/52 some retinal ganglion cells resemble their adult counterparts based on morphological analogy (see Figs. 7 and 8). By comparing the morphology of neighboring ganglion cells as described above and by measuring their soma and dendritic field dimensions, some of the cells in the scatter plots could be provisionally classified as alpha- or beta-like. Cells classified in this way are represented in Figure 10 by the filled triangles (alpha cells) and circles (beta cells), while the rest of the population is indicated by the open symbols. The scatter diagrams indicate that at every age from E50/52 onwards, the cluster of cells with medium-sized somata but the smallest dendritic trees contains many beta-like ganglion cells (compare the cells in column A in Figs. 8 and 9 with the filled circles labeled A in Fig. 10). In contrast, the group of cells in each scatter plot having the largest somata and relatively large dendritic trees contains many alphalike cells (compare column B in Figs. 7 and 8 with the filled triangles labeled B in Fig. 10). In addition, between E50/52 and P31 the clusters corresponding to cells morphologically resembling alpha and beta classes becomes progressively more segregated from the rest of the population, so that by P31 cells belonging to these 2 classes have separated into the distinct clusters similar to that seen in the adult (Boycott and Wässle, 1974). This analysis provides support for the suggestion that as early as E50/52 some ganglion cells resembling the alpha and beta cells of the adult can be recognized.

In performing the analysis described above, care was taken to make measurements on ganglion cells located at similar distances from the central retina because, as in the adult, during development cell size could vary with retinal eccentricity (Boycott and Wässle, 1974; Dann et al., 1987). However, it was of interest to examine whether the correlation between cell size and eccentricity is present prenatally. To do so, we plotted the soma diameter (Fig. 11, top) and the dendritic field diameter (Fig. 11, bottom) of beta cells as a function of distance from the estimated area centralis (see Materials and Methods and Fig. 2) at E57 (open circles) and E63 (filled circles). We used the population of beta cells at these ages because the sample included a few injected in the central retina, as well as those located more peripherally. Figure 11 shows that the dendritic diameter of beta cells at E57 (open circles) and E63 (filled circles) is clearly cor- 

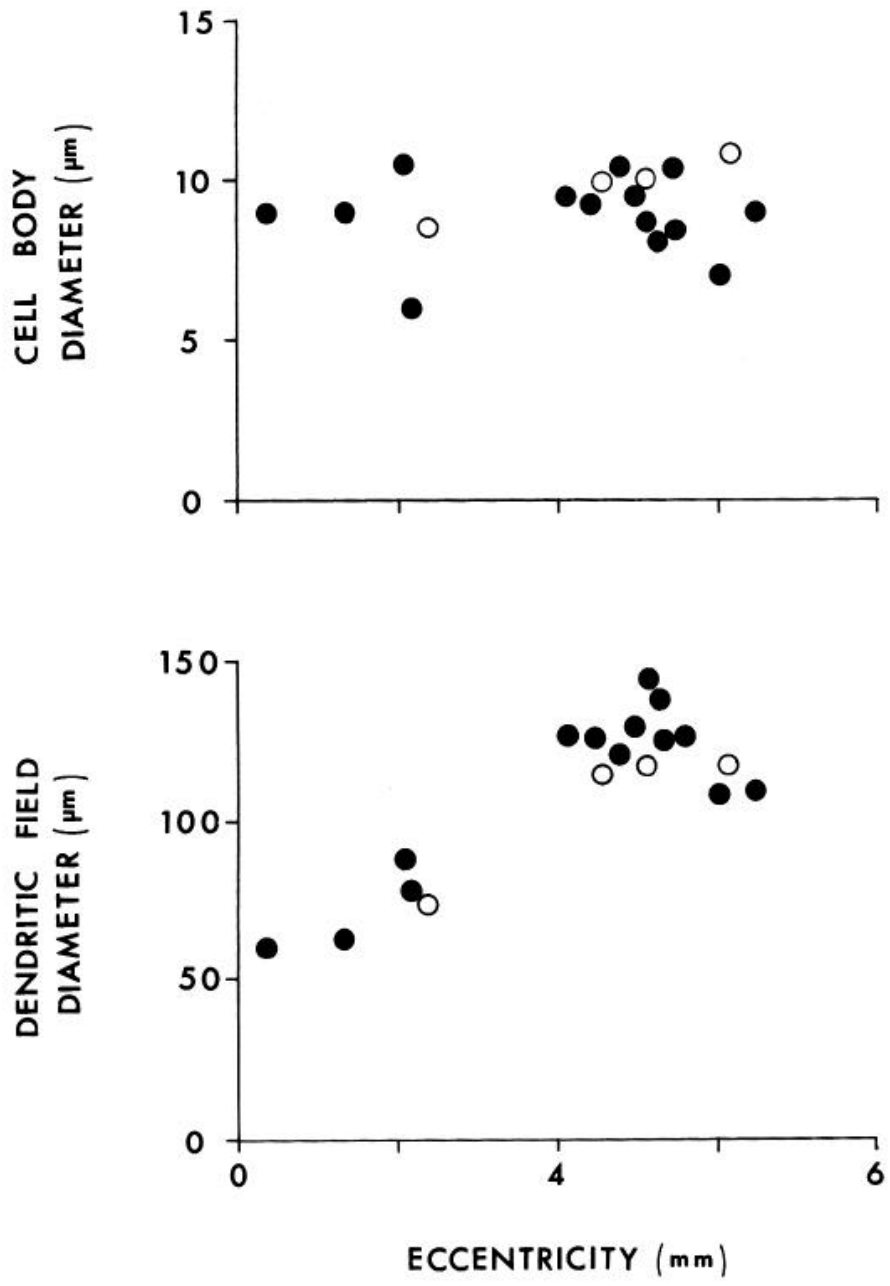

Figure 11. Two scatter diagrams showing mean cell body diameter (top) and mean dendritic field diameter (bottom) of beta cells at E57 (open circles) and E63 (filled circles) expressed as a function of distance from the estimated area centralis (eccentricity; see Materials and Methods). These graphs show that at these late prenatal ages beta cells located in peripheral retina have larger dendritic fields but similar sized somata to those located more centrally.

related with distance. At both ages, the dendritic trees of cells located within $3 \mathrm{~mm}$ of the central region are $<100 \mu \mathrm{m}$ in diameter while those of cells in the periphery are always $>100$ $\mu \mathrm{m}$. Soma size, however, does not change appreciably with eccentricity, although it is known to do so in the adult (Boycott and Wässle, 1974). Thus, at least by a week before birth, beta cells do vary in size with eccentricity, but the variation is not as pronounced as in the adult.

Another characteristic feature of mature retinal ganglion cell morphology is the tendency for dendritic trees to remain restricted either within the inner or outer half of the inner plexiform layer (Nelson et al., 1978; Peichl and Wässle, 1981; Saito, 1983). While it was not possible to examine directly the development of dendritic sublamination because of the use of the whole-mount preparations here, it was possible to infer whether sublamination is present prenatally by comparing, for neighboring cells of a given class, the depth at which the major portion of the dendritic tree is in focus. Figure 12 shows a photograph of 4 LY-filled beta cells in close proximity from an animal at E63. The dendritic trees are clearly not at a similar depth in the

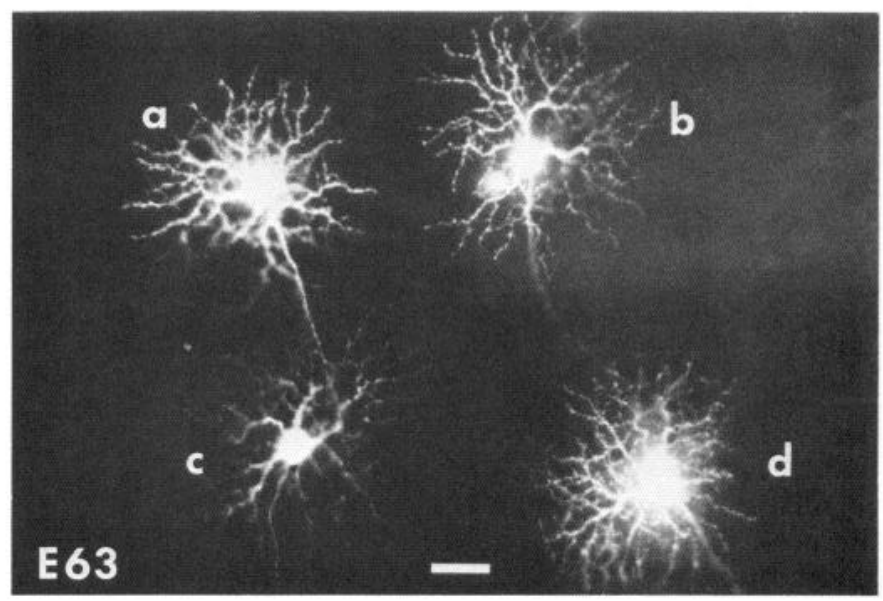

Figure 12. Injections of LY into 4 neighboring rhodamine-labeled beta cells at E63 demonstrate the variability of their dendritic stratification within the retina. The dendrites of cells $a$ and $d$ are in focus and appear to ramify mainly towards the vitreal surface; those of cell $c$ are out of focus and seem to be further from the vitreal surface. The dendrites of cell $b$ appear to branch throughout. This figure therefore suggests that at E63 there is some segregation of dendritic trees into different sublaminae of the inner plexiform layer. The axon of all 4 cells arises from the bottom and right of the soma. Scale bar, $20 \mu \mathrm{m}$.

inner plexiform layer since those of cells $\mathrm{a}, \mathrm{b}$, and $\mathrm{d}$ are in focus, while that of cell $\mathrm{c}$ is out of focus. When the focal plane is closer to the outer half of the inner plexiform layer, the dendrites of cell c can be sharply resolved; further, part of the dendritic tree of cell $b$ can be followed into this region. These incidental observations suggest that by E63 the dendritic trees of some ganglion cells (e.g., Fig. 12: cells a, c, and d) may already be restricted to different sublaminae of the inner plexiform layer.

\section{Transient features of ganglion cell morphology}

The results presented above suggest that by about 2 weeks before birth some ganglion cells resembling the adult classes can be recognized based on a comparison of soma sizes and dendritic spread of nearby cells. However, careful inspection of the LY-filled ganglion cells in late prenatal and early postnatal life suggests that superimposed upon the basic dendritic patterns characteristic of the adult cells are distinct and transient morphological features. Ganglion cells at these ages appear to have excessive numbers of dendrites and spines, as shown in the line drawings of Figures 7 and 8 . In these examples, the profusion of spines and branches is most evident at P3, but by P31 the cells resemble the adult more closely, with far fewer spines. A striking illustration that dendritic trees become simplified with age is shown by direct comparison in the photomicrographs of 2 cells in Figure 13. The smaller of these cells was obtained from a cat at P8 (Fig. 13A) and the other from an adult (Fig. $13 B$ ). Both cells were classified as alpha because they have the largest cell bodies and large, characteristically shaped dendritic trees when compared with neighboring neurons in the same retina. However, the complex dendritic branching pattern of the cell at P8 contrasts with the smoother, less branched dendrites found in the adult. Thus, while both belong to the same class, the younger cell is not just a miniature replica of the mature neuron.

Spines are also present in profuse numbers along the dendrites and even the somata of many ganglion cells throughout the perinatal period (see especially Fig. 8, P3: $B$ and $C$, also Ramoa 

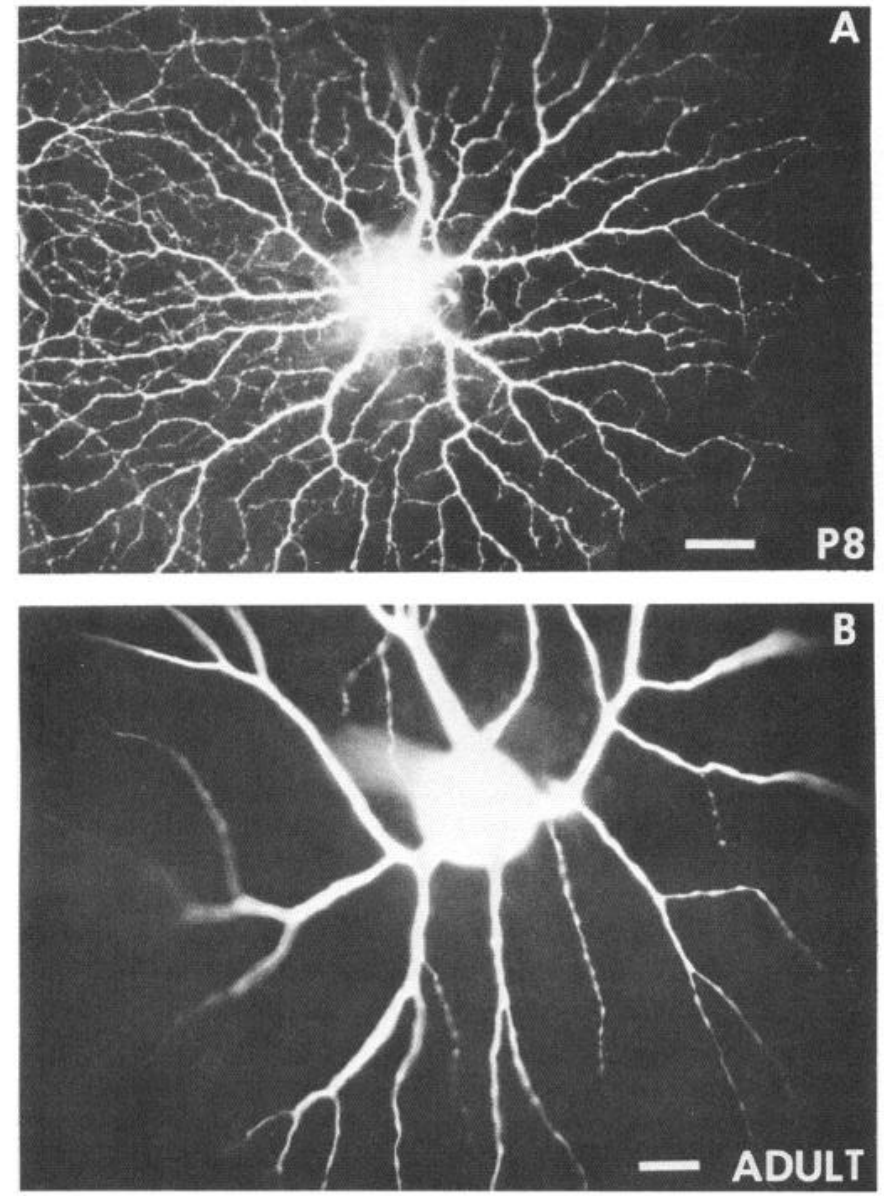

Figure 13. Two alpha cells at $\mathrm{P} 8(A)$ and adult $(B)$ are shown to compare dendritic complexity. Note at P8 the large number of dendritic branches and spines, and in the adult the relatively few dendritic branches with no spines. The dendrites of the cell in $A$ overlap the dendrites of an adjacent LY-filled cell on the left. Cell $A$ is double-labeled. Scale bar, $20 \mu \mathrm{m}$.

et al., 1987, fig. 2B for somatic spines). The detailed morphology of these spines can be seen in the high-power views of 2 LY-filled cells shown in Figure 14. The proximal dendrites of a cell filled at E57 (Fig. 14A) are studded with fine processes of varying length, many of which are tipped with growth cones or filopodia. By P15, as shown in Figure $14 B$, many cells have dendritic appendages more typical of adult spines in that they are rather short and club-like in appearance.

These incidental observations suggest that dendritic remodeling involving a loss of spines and perhaps even a simplification of dendritic branching is required for ganglion cells to mature into their adult counterparts. To investigate this suggestion further, we made 2 separate sets of measurements on drawings of each LY-injected cell between E45 and adult in order to obtain information on the time course and numbers of transient dendritic features. In one set of measurements, we counted the total number of dendritic spines on each cell (somatic spines were excluded). A process was considered a spine if it was $\geq 5 \mu \mathrm{m}$ long (see Materials and Methods). The results were compiled into a histogram for each age studied (Fig. 15, left). In the second set of measurements, the total number of dendritic branch points was counted for each cell. A branch point was defined as any point of bifurcation in which the 2 resulting processes are $>5$ $\mu \mathrm{m}$ or in which the resulting process, regardless of length, gives
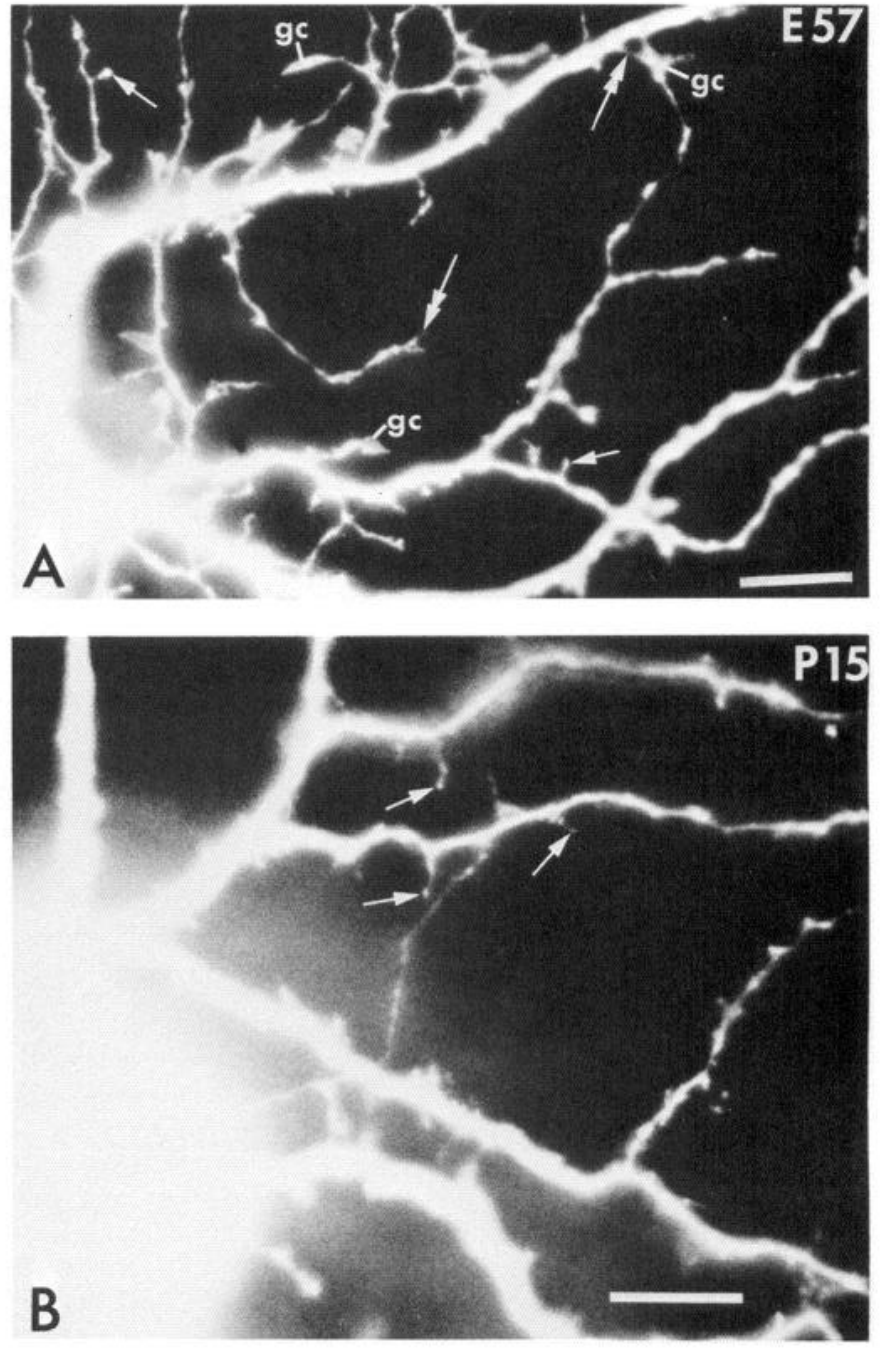

Figure 14. LY-filled ganglion cells illustrating different types of transient dendritic appendages present during development. A, At E57, dendrites can give rise to many different types of processes, some of which often end in small growth conelike structures $(g c)$; some appendages and gc's give rise to fine filopodia (double arrows) and some small clublike spines (arrows) are also present. B, At P15, short clublike dendritic spines predominate (arrows). A camera lucida drawing of cell $A$ is shown in Figure 7C: E57. Cell $A$ is double-labeled. Scale bar, 10 $\mu \mathrm{m}$.

rise to yet another branch. Again the results were compiled in histogram form for each age (Fig. 15, right).

The results of this analysis show that ganglion cells are initially very simple, with $<50$ dendritic spines or branch points per cell at E45. Over the next 3 weeks, cells increase in dendritic complexity, so that by birth about $80 \%$ of the cells have $>100$ spines per cell (Fig. 15, left: P3) and about $60 \%$ of the cells have $>100$ branch points per cell (Fig. 15, right: P3). In fact, it is worth noting that during the first 2 postnatal weeks many cells are extremely complex, with hundreds of spines and branch points. These numbers contrast with those in the adult, in which none of the ganglion cells in our sample had $>100$ spines per cell, and only about $5 \%$ had $>100$ branch points per cell (see Fig. 15).

To examine the time courses of these changes in spines and dendritic branches, the median value for each histogram dis- 


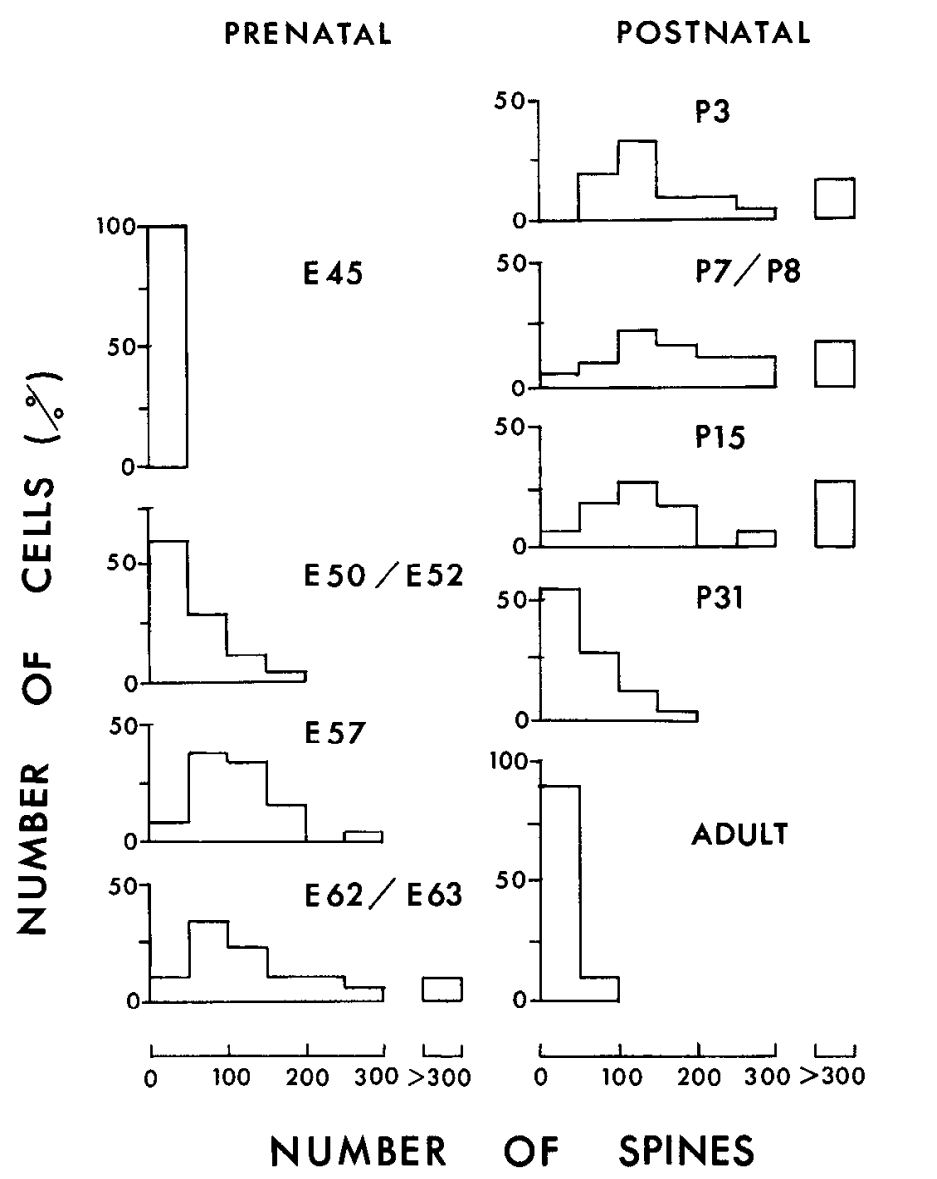

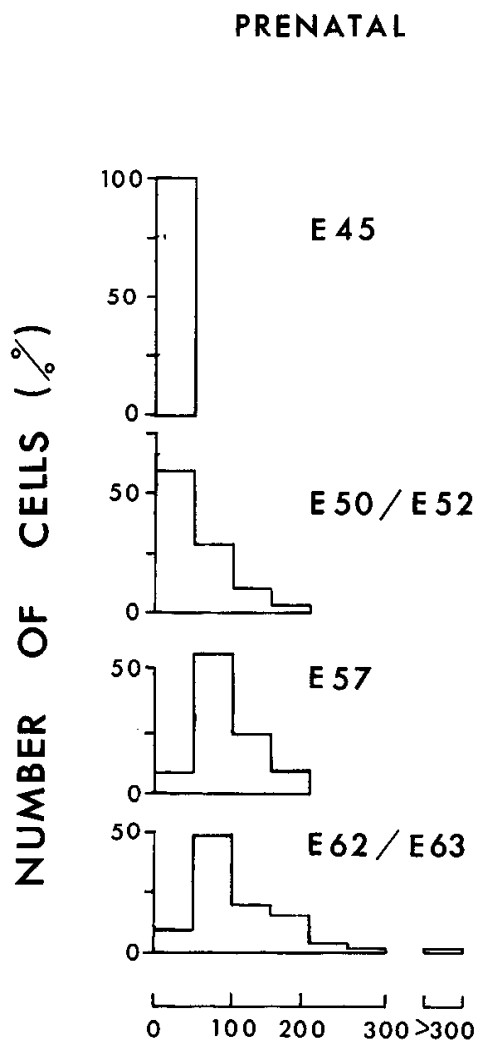

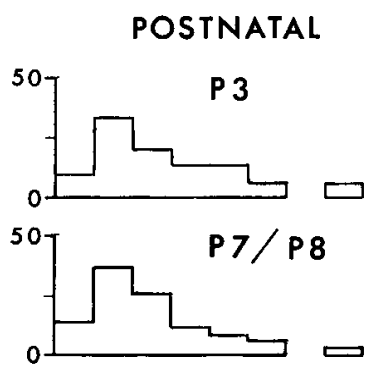

NUMBER OF BRANCH POINTS

Figure 15. Histograms showing the total number of dendritic spines (left) and the total number of dendritic branch points (right) on ganglion cells analyzed at prenatal (E45, $n=18 ; \mathrm{E} 50 / 52, n=28 ; \mathrm{E} 57, n=27 ; \mathrm{E} 62 / 63, n=58)$ and postnatal ages $(\mathrm{P} 3, n=25 ; \mathrm{P} 7 / 8, n=41 ; \mathrm{P} 15, n=18 ; \mathrm{P} 31$, $n=26$; Adult, $n=20$ ). Both illustrations demonstrate that the number of cells having many spines and branch points begins to increase at about E50/52. This number peaks in early postnatal life and then gradually declines to relatively low values in the adult.

tribution was calculated, and the results are plotted in the curves of Figure 16. The time courses of the changes are similar for both spines and branch points. Dendritic complexity reaches a peak by about $\mathrm{P} 3$ and then falls abruptly during the first postnatal month. However, adult values are not quite present even by P31. Thus, the period beginning 3 weeks before birth and ending about 3 weeks after birth is one in which a great deal of dendritic remodeling occurs.

In view of these observations we wondered if different ganglion cell types undergo different degrees of dendritic remodeling and, if so, whether these occur simultaneously. To answer these questions, we took advantage of the finding described above that by about E50 it is possible to assign ganglion cells to the alpha and beta classes. Therefore, the median values of dendritic branch points and spines were calculated separately for alpha and beta cells (Fig. 17; see also Table 2, which shows the medians and ranges for each measurement plotted in Fig. 17). Inspection of the curves indicates that both alpha and beta cells undergo extensive remodeling of spines and dendritic branches. For both cell classes, the numbers of spines and branch points reach a peak around the first week of postnatal life. Moreover, the time course of the changes are similar to that of the overall population (cf. Figs. 16 and 17). On the other hand, the curves of Figure 17 imply that alpha cells undergo more extensive remodeling than do beta cells in view of the fact that higher numbers of spines and branch points are attained in development. It must be remembered that alpha cells have much larger dendritic trees than beta cells and would therefore be expected to attain higher absolute numbers of transient processes than beta cells. Nevertheless, the fact that the numbers of spines and branch points found on both alpha and beta cells in the adult are roughly equal suggests that alpha cells may indeed undergo more remodeling.

Another morphological feature occasionally observed in the immature ganglion cells is the tendency for the tips of dendrites to be in very close proximity to each other. This finding is illustrated in Figure 18 for 2 cells at E57. These neighboring cells are located close to each other, so that their dendritic trees overlap (Fig. 18A). A higher-magnification photo of the region of overlap (Fig. 18B) reveals that in at least 3 locations (indicated by the arrows) the tips of the dendrites of one cell end in such close proximity to the dendritic processes of the other cell that they appear to make physical contact. This is the case at even higher magnification $(630 \times)$, as shown in Figure $18 C$, where the processes of both ganglion cells are shown in the same focal plane.

In addition to the transient dendritic features of ganglion cell development, exuberant processes originating from the intraretinal portion of axons are present early in development and 

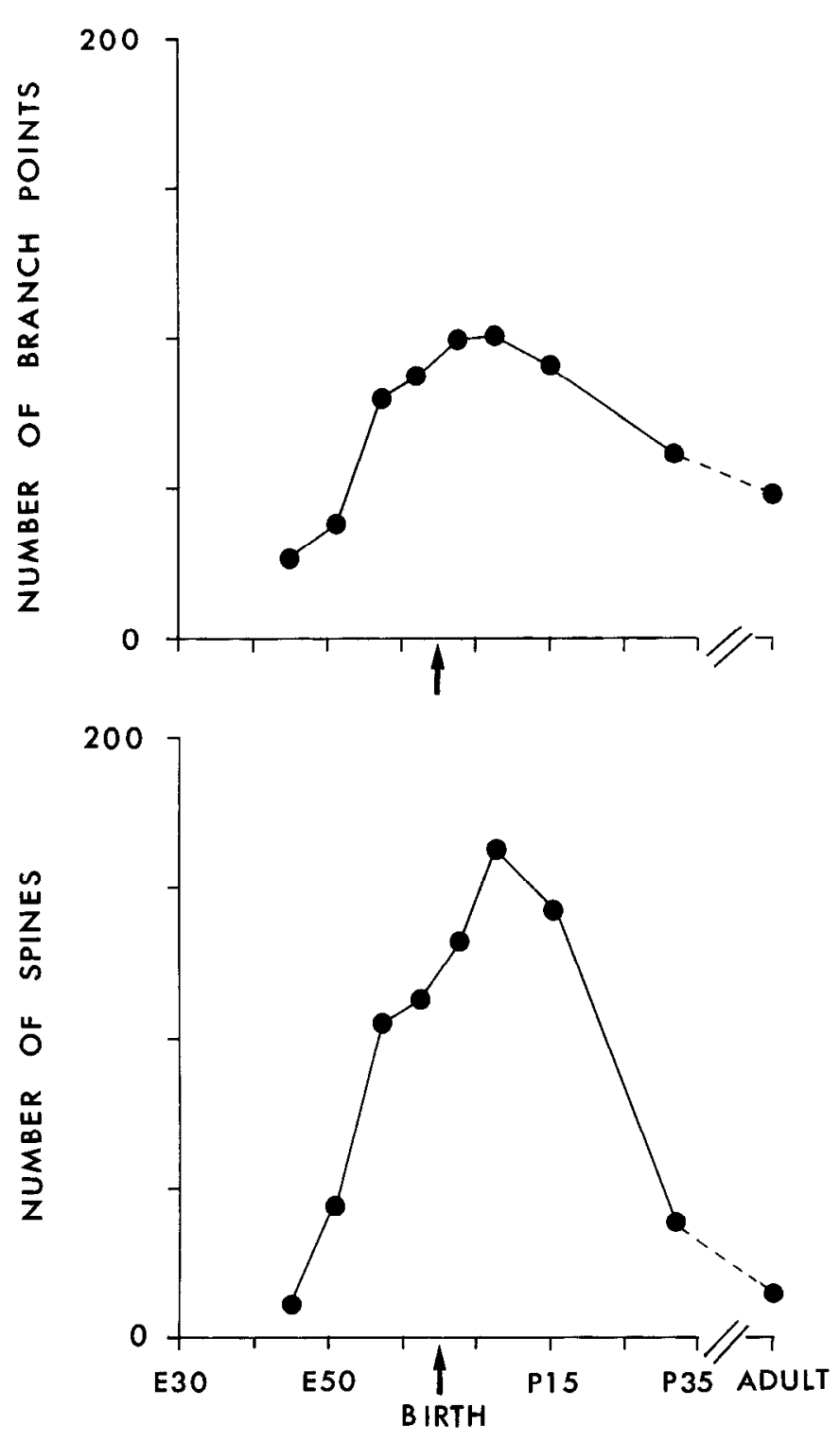

Figure 16. Graphs showing the time course of change in dendritic complexity for all types of ganglion cells. The median values of branch point number (top) and spine number (bottom) derived from the histograms of Figure 15 are plotted as a function of age. The median value for both types of dendritic complexity reaches a maximum in early postnatal life $($ Birth $=$ E65).

disappear by adulthood. One of the main characteristics of immature axons is the presence of delicate short processes given off the axon. These processes - "side branches"-are found on axons in at least half of the cells between E35 and P32, but not in the adult (see Table 3). As shown in Figure 19, most are simple, unbranched processes, usually $<10 \mu \mathrm{m}$ long; some are very smooth and resemble filopodia (Fig. 19F), while others have a more beaded appearance (Fig. 19A). It is also clear from this figure that most side branches are located along the axon in the vicinity of the soma. However, some side branches can be observed along the course of the axon within the optic fiber layer as far away as a few hundred microns from the point of axon origin (Fig. 19B), thus confirming that these transient processes arise from axons, rather than from dendrites.

Another transient axonal feature is the presence of bifurca-
Table 2. Developmental changes in the dendritic complexity of ganglion cells

\begin{tabular}{|c|c|c|c|c|c|c|}
\hline \multirow[b]{2}{*}{ Age } & \multicolumn{3}{|c|}{ Beta cells } & \multicolumn{3}{|c|}{ Alpha cells } \\
\hline & $n$ & \multicolumn{2}{|c|}{ Median Range } & $n$ & \multicolumn{2}{|c|}{ Median Range } \\
\hline \multicolumn{7}{|c|}{ A. Analysis of spines } \\
\hline E50/52 & 4 & 20 & $9-45$ & 3 & 46 & $25-94$ \\
\hline E57 & 4 & 64 & $54-102$ & 9 & 104 & $79-196$ \\
\hline $\mathrm{E} 62 / 63$ & 24 & 84 & $33-122$ & 10 & 231 & $99-393$ \\
\hline P3 & 10 & 121 & $50-168$ & 6 & 445 & $175-742$ \\
\hline $\mathrm{P} 7 / 8$ & 17 & 116 & $63-174$ & 8 & 361 & $142-577$ \\
\hline P15 & 10 & 106 & $45-158$ & 5 & 315 & $158-378$ \\
\hline P31 & 9 & 38 & $4-77$ & 6 & 19 & $1-80$ \\
\hline Adult & 1 & 12 & 12 & 10 & 5 & $0-24$ \\
\hline \multicolumn{7}{|c|}{ B. Analysis of branch points } \\
\hline $\mathrm{E} 50 / 52$ & 4 & 36 & $30-53$ & 3 & 58 & $33-176$ \\
\hline E57 & 4 & 68 & $51-80$ & 9 & 112 & $74-158$ \\
\hline E62/63 & 24 & 70 & $40-88$ & 10 & 115 & $59-250$ \\
\hline P3 & 10 & 97 & $68-189$ & 6 & 157 & $80-330$ \\
\hline $\mathrm{P} 7 / 8$ & 17 & 75 & $45-229$ & 8 & 169 & $24-276$ \\
\hline P15 & 10 & 70 & $51-99$ & 5 & 100 & $78-181$ \\
\hline P31 & 9 & 79 & $39-111$ & 6 & 77 & $46-255$ \\
\hline Adult & 1 & 77 & 77 & 10 & 52 & $41-98$ \\
\hline
\end{tabular}

tions that give rise to axon collaterals, some of which travel for long distances beyond the dendritic field of the injected ganglion cell. Cells with bifurcating axons are present in greatest numbers throughout fetal and neonatal life but decline after P8. As shown in Table 3, between 5 and 14\% of injected cells from E35 to P8 have axon collaterals, whereas after $\mathrm{P} 8$, no collaterals were found on 91 cells studied.

Examples of several cells with bifurcating axons at different ages are shown in the camera lucida drawings of Figure 20, left. The E63 cell shown in Figure $20 \mathrm{~A}$ has a main axon that travels lowards the optic disk (arrow). However, 2 collaterals branch from the main axon, both of which ramify within the optic fiber layer in close proximity to the cell of origin. A high-power view of the axon at the points of bifurcation is shown in Figure 20, right. Note that in this and the subsequent examples shown in Figure 20, right, the axons are most likely located in the optic fiber layer since they are clearly in a focal plane closer to the vitreal surface than the underlying dendrites. Figure $20 \mathrm{~B}$, left, shows 2 LY-filled cells at E52. Five axons can be seen, 3 of which originate from one of the cells. Each cell gives rise to only one axon that is appropriately directed towards the optic disk (arrow). The other axons could be traced for long distances within the optic fiber layer. Figure $20 \mathrm{~B}$, right, shows a highpower photo of the region of bifurcation that gives rise to the appropriately directed axon and its orthogonal collateral for the 3 -axon cell. Finally, Figure $20 \mathrm{C}$, left, and $20 \mathrm{C}$, right, shows P8 cell with a bifurcating axon. Again, only one collateral travels in the direction of the optic disc. However, this need not be the case, since occasionally both collaterals are directed correctly towards the disc. These results cannot be explained by axons en passage being damaged and filled by the microelectrode because in each case only one injection was made within the soma, and the axon bifurcations occur some distance away. Thus, these observations indicate that ganglion cells exhibit transient features with respect to axonal as well as dendritic morphology. 


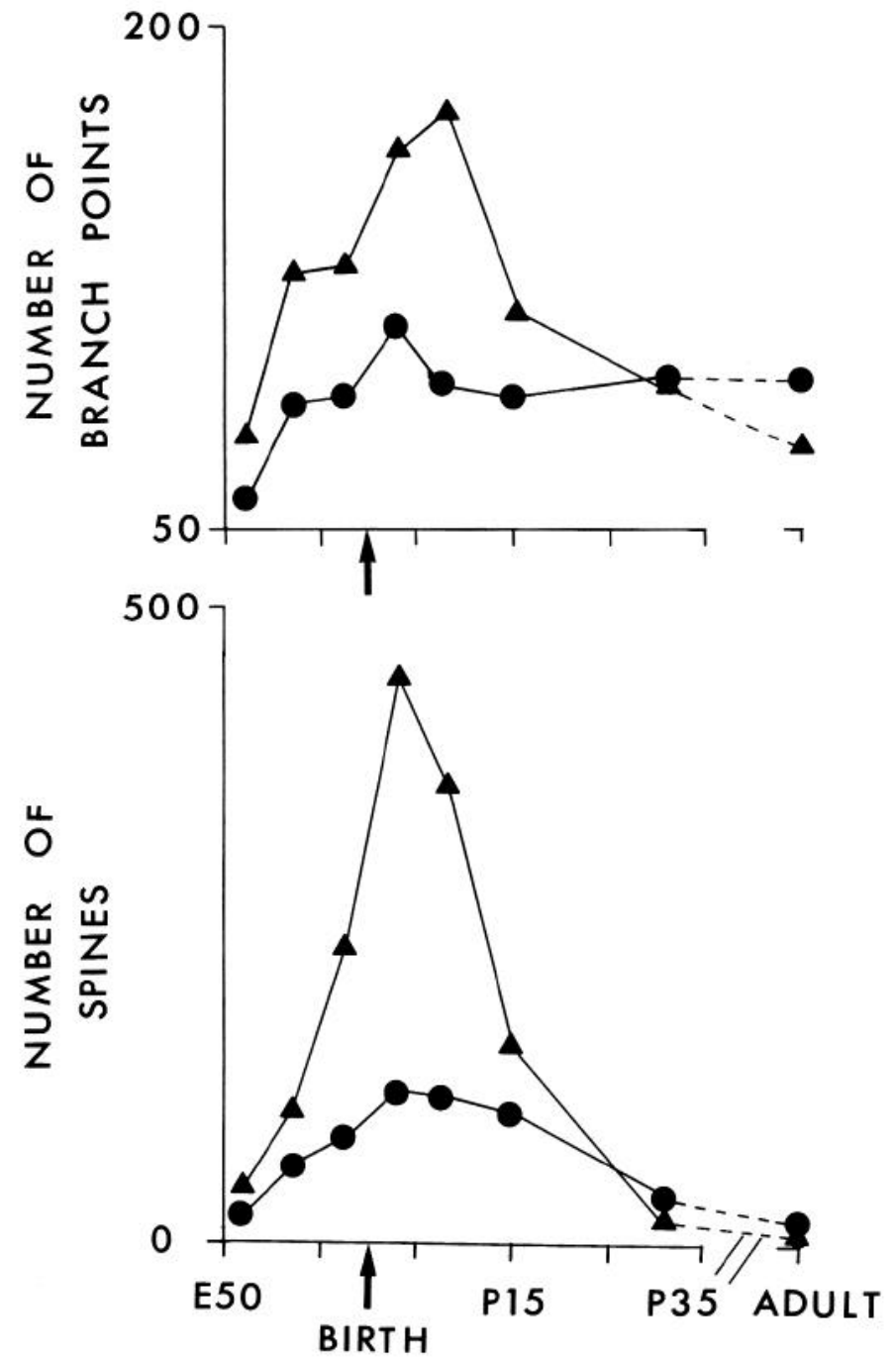

Figure 17. Graphs showing the time course of change in dendritic complexity for alpha (triangles) and beta (circles) cells. The median values for branch point number (top) and spine number (bottom) derived from Figure 15 and Table 2 are plotted as a function of age. Note that the time course of dendritic remodeling is similar for alpha and beta cells, as well as for the ganglion cell population as a whole (cf. Fig. 16) $($ Birth $=$ E65).

\section{Discussion}

The results of this study show that in the cat, retinal ganglion cells achieve their adult form by a combination of growth and remodeling. At the earliest ages studied (E35-45), ganglion cells are morphologically simple, but by E50 they have achieved sufficient dendritic growth that their basic forms resemble those of mature ganglion cells belonging to the alpha, beta, or gamma classes. However, at this age 2 features distinguish these cells from the adult: They are smaller, and they exhibit a variety of exuberant processes, including excessive dendritic spines and branches, axonal side branches, and collaterals. Our quantitative analysis indicates that the degree of exuberance as assessed by counting the number of spines and branch points increases steadily from E45 to reach a peak during the first week of postnatal life, following which there is a fall to almost adult values by the end of the first month. Moreover, the soma and dendritic field diameters of retinal ganglion cells increase throughout this period; even by P31, however, considerable dendritic and so-
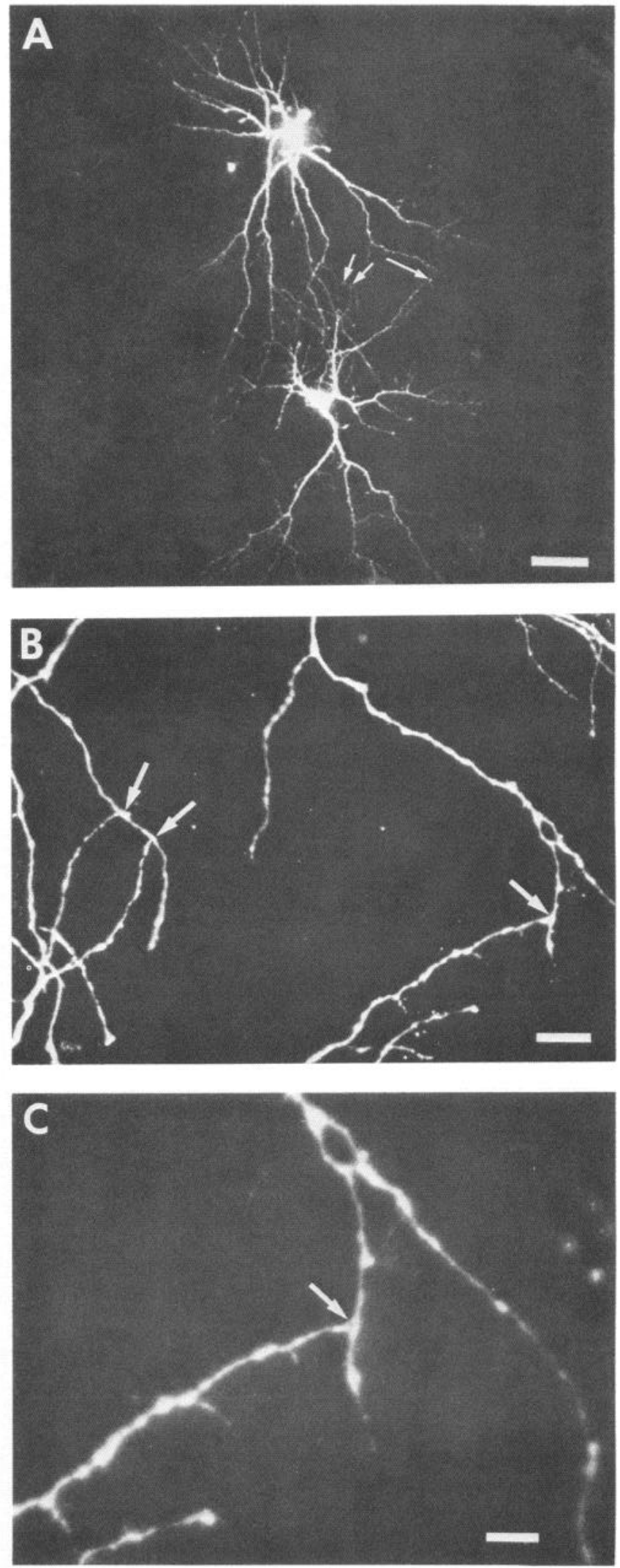

Figure 18. The dendrites of neighboring ganglion cells can come into very close proximity with each other. Two double-labeled ganglion cells at E57 are shown in LY fluorescence. The tips of 3 dendrites of the lower cell in $A$ appear to contact 2 of the dendrites of the upper cell (arrows). These 3 appositions are enlarged in $B$ (arrows) and the righthand apposition (long arrow in $A$ ) is further enlarged in $C$. Scale bars: $A, 50 \mu \mathrm{m} ; B, 10 \mu \mathrm{m} ; C, 5 \mu \mathrm{m}$. 
matic growth must still occur in order to achieve the adult dimensions.

\section{Growth of ganglion cells}

Ganglion cells in peripheral retina - the focus of this studycontinue to grow at times well beyond those in central retina. For example, at E57-63 the dendritic diameters of beta cells at 1-2 mm eccentricity are essentially full size, while those at 4$5 \mathrm{~mm}$ eccentricity have reached only about $50 \%$ of their adult size (compare Fig. 12 with Boycott and Wässle, 1974, fig. 7). (It is worth noting, however, that while dendritic arbors appeared mature, the soma diameters of the central beta cells in our sample at E57-63 are only $60 \%$ of adult size.) On the other hand, ganglion cells continue to grow in peripheral retina even after P31. Comparison of the average soma and dendritic field diameters of alpha and beta cells at P31 (see Fig. 10) with those of their adult counterparts at an equivalent eccentricity in peripheral retina (Boycott and Wässle, 1974: see Figs. 7 and 9 at $7 \mathrm{~mm}$; see also Dann et al., 1988) indicates that both cell types are only within $60-70 \%$ of their adult size at about 1 month after birth. This observation also suggests that, at least for peripheral retina at P31, neither alpha nor beta cells are ahead of the other with respect to rate of maturation.

The continued growth and development of peripheral ganglion cells well into postnatal life observed here in the cat retina is reminiscent of the constant addition and growth of ganglion cells at the retinal margins in fish (Hitchcock and Easter, 1986), but the 2 species differ in several fundamental respects. The fish retina grows throughout life both by the addition of newly generated ganglion cells at the ciliary margin and by the constant growth of centrally situated ganglion cells (Johns and Easter, 1977; Hitchcock and Easter, 1986). In contrast, in the cat retina, as in all mammals, ganglion cells are generated during a brief prenatal period between E21 and 31 in the cat (Kliot and Shatz, 1982; Walsh et al., 1983; Walsh and Polley, 1985), and postnatally only photoreceptors and interneurons outside the central retina are generated (Johns et al., 1979). Moreover, our results suggest that beta cell dendrites in central retina have achieved their adult sizes by E57/63, while the dendrites and somata of both alpha and beta cells in peripheral retina continue to grow even after one month postnatally (see also Rapaport and Stone, 1983; Dann et al., 1987, 1988). Thus, the pattern of retinal growth in the cat is different from that found in the fish, and the continued growth of peripheral ganglion cells is not related directly to the spatiotemporal pattern of ganglion cell neurogenesis. On the other hand, the continued growth of peripheral ganglion cells in the cat is entirely consistent with the results of previous studies showing that retinal growth is nonuniform, with central retina growing very little even during prenatal life, compared with peripheral retina, which continues to expand well into postnatal life (Mastronarde et al., 1984; Lia et al., 1987; Robinson, 1987). Thus, the factors responsible for the differential growth of the retina, such as the ongoing genesis of photoreceptors, could also play a role in controlling the growth of ganglion cell dendrites.

\section{Identification of ganglion cell types}

We have assumed that it is indeed possible to recognize and classify cells according to their adult types during development, at least after E50. We believe this assumption is valid for several reasons. The first is that cells resembling alpha, beta, and gamma cells of the adult by virtue of their characteristic dendritic mor-
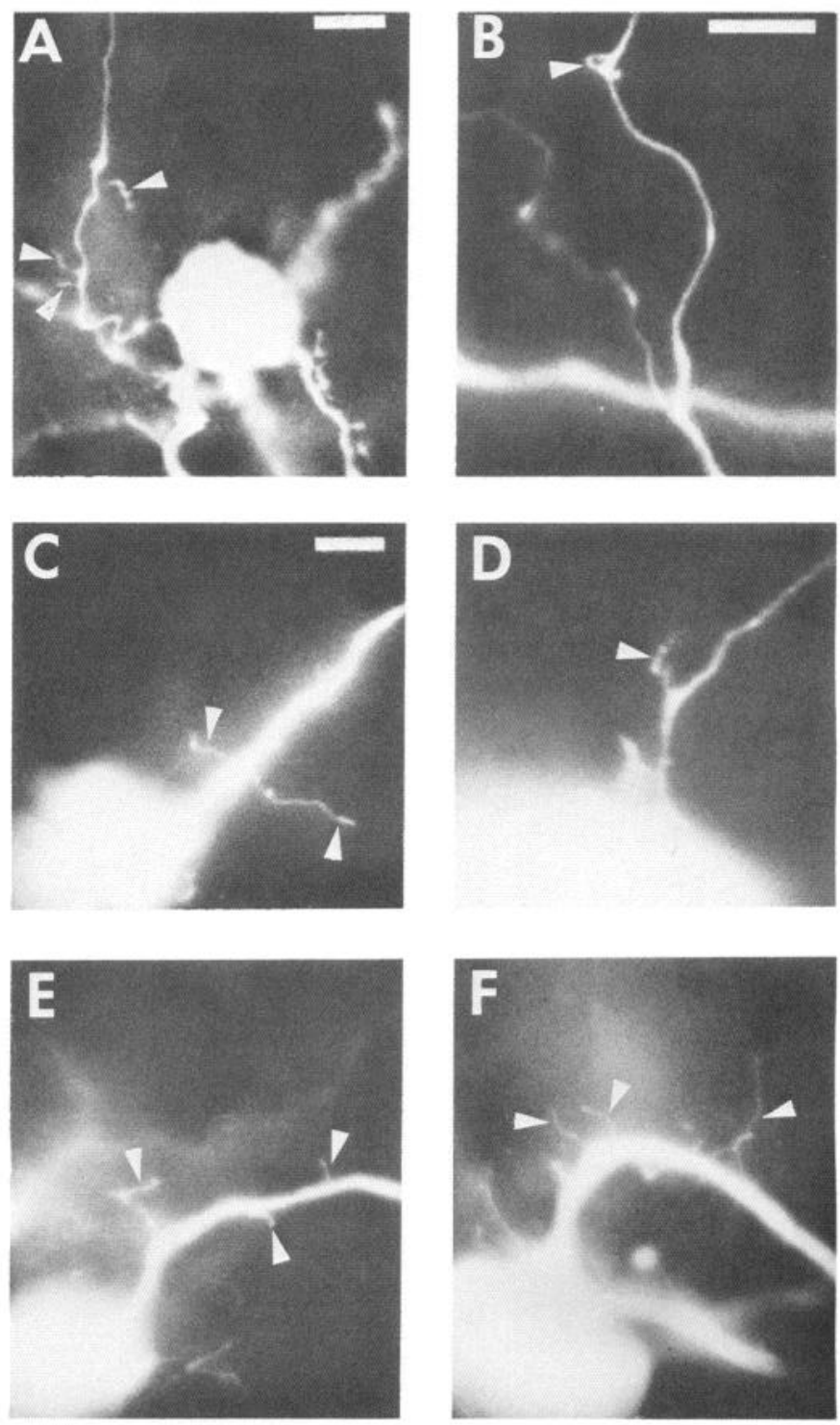

Figure 19. Photographs of LY-filled ganglion cells between E45 and P32 illustrating the presence of small side branches (arrowheads) usually given off along the proximal portion of the axon. $A, \mathrm{E} 45 ; B, \mathrm{E} 50 ; C$, $\mathrm{E} 63 ; D, \mathrm{P} 8 ; E$ and $F, \mathrm{P} 32$. These processes are usually short and unbranched, can have a varicose appearance $(A)$ or be very fine, resembling filaments or filopodia $(F)$. They are most easily photographed on proximal axon segments, where they are prominent $(A, C-F) . B$ shows that some side branches also arise from more distant axonal regions, in this case distal to an axonal bifurcation (see also Fig. 8, cells $A$ and $E$ at E50/52 and cells $B$ and $E$ at E45). All cells were double-labeled, except that shown at E45 in $A$. Scale bars: $A, 10 \mu \mathrm{m} ; B$ and $C, 5 \mu \mathrm{m} ; D-F$, same as $C$.

phologies can be found near each other at the same eccentricity by E50. Second, the results of the quantitative analysis shown in the scatter plots of Figure 10 suggest that when the morphology of cells is taken into account in conjunction with soma and dendritic field measurements, then many ganglion cells resembling the alpha and beta classes fall into separate clusters that occupy positions on the scatter plots reminiscent of those found in the adult. While the separation between clusters is not as clear-cut as that seen in the adult, it is consistent with the notion that even in development each cell type exhibits its own characteristic signature with respect to its morphological dimensions. 


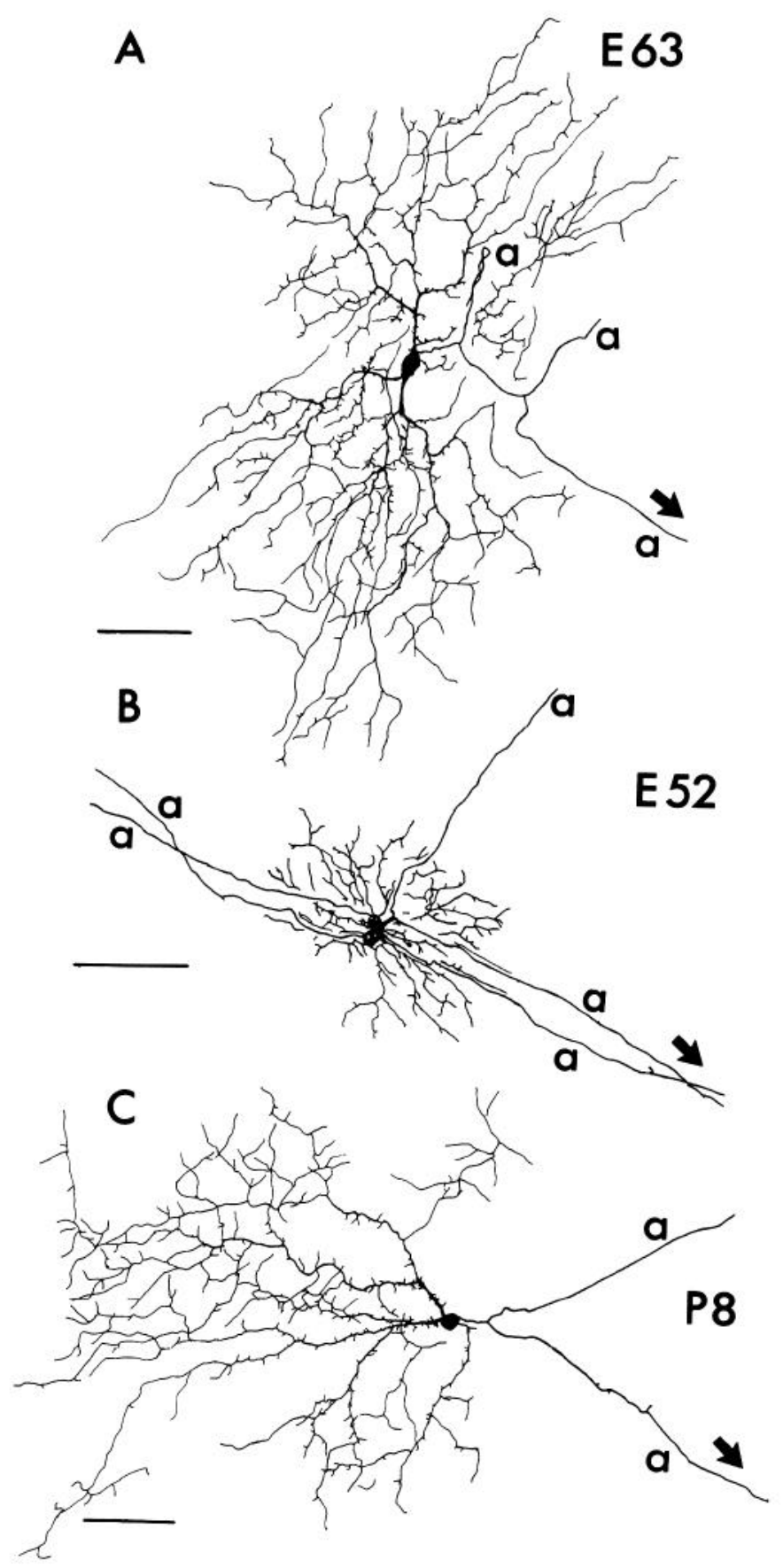

Figure 20. Camera lucida drawings (left) and corresponding photographic enlargements (right) showing that retinal ganglion cells can have more than one axon or axon bifurcation $(a)$ during development. Cell $A$ at E63 has an axon that heads in the direction of the optic disk (arrows,

While these considerations permit us to be reasonably confident about the identification of alpha and beta cells during development, the situation with respect to other ganglion cell classes is not as straightforward, in part because less is known even in the adult. For example, the cells illustrated in column E of Figures 7 and 8 were selected for illustration based on their extreme position in the scatter plots with regard to large dendritic field and small soma diameter. In the adult, cells with this combination of dimensions are frequently gamma cells (Boycott and Wässle, 1974), and the cells illustrated in column
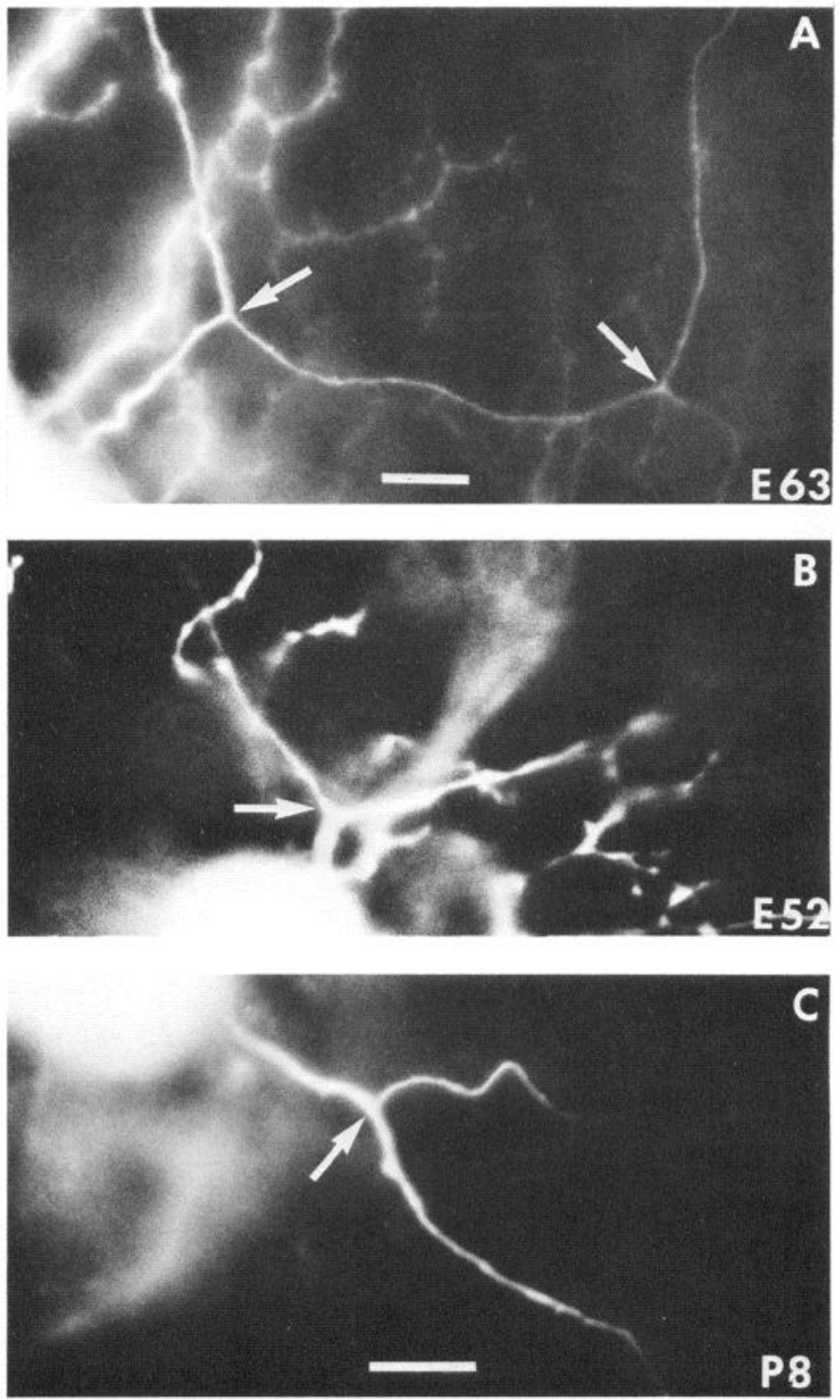

left) and gives rise to 2 collaterals (arrows, right, mark branch points), the proximal one of which loops and courses back along its original path. $B$ illustrates 2 dye-coupled cells that give rise to a total of 5 axons. One axon from each cell runs towards the optic disc (arrow, left), and one axon from each cell runs directly away from the optic disc. An axon bifurcation close to the soma is also present on the upper cell (arrow, right). Ganglion cell $C$ at P8 gives rise to an axon that bifurcates near the soma (arrow, right). Only one branch (arrow, left) is directed correctly toward the optic disc. Cells $A$ and $C$ were double-labeled. Some dendrites and axons (left) have been coarsened in the interest of reproduction. Scale bars: Left, $50 \mu \mathrm{m}$; right, $A, 10 \mu \mathrm{m} ; B$ (same bar as in $A$ ), $5 \mu \mathrm{m}$; $C, 10 \mu \mathrm{m}$.

E of Figures 7 and 8 have morphologies consistent with their adult counterparts from E50/52 onwards. However, cells illustrated in columns $\mathrm{C}$ and D of Figures 7 and 8 are morphologically heterogeneous throughout development, and we could not classify them.

We have shown that cells resembling alpha, beta, and gamma cells are present by E50 in peripheral retina, the focus of our study. These cell types may be distinguishable even earlier in central retina, in view of the rough central to peripheral gradient of retinal neurogenesis and maturation (Walsh and Polley, 1985; 
for review, see Shatz and Sretavan, 1986). The question remains whether the cells identified as alpha, beta, and gamma at E50 will develop into their adult counterparts. We think this is quite likely, in part because beta cells in central retina are almost their adult size by E57 (see Figure 11).

\section{Remodeling of ganglion cells}

The results of our study have confirmed and extended those obtained from previous morphological studies of cat retinal ganglion cell development. Golgi studies of postnatal retina had indicated that alpha and beta cells can be identified by 3 weeks (Rusoff and Dubin, 1978; Rusoff, 1979). A recent study in which ganglion cells were labeled by means of extracellular injections of HRP has also suggested that these 2 cell types can be recognized by inspection as early as E50 (Maslim et al., 1986)-a suggestion that receives direct support from the results of our quantitative analysis. However, neither of these studies remarked on the striking dendritic and axonal exuberance that we have found also characterizes the fetal and neonatal appearance of cat retinal ganglion cells, a result that has recently received independent confirmation from Dann et al. $(1987,1988)$, who observed that early postnatal alpha and beta cells have excessive numbers of dendritic spines. In view of our finding that the degree of dendritic branching and the number of dendritic spines has declined considerably by 3 weeks after birth (Figs. 16, 17), it is perhaps not surprising that Rusoff and Dubin (1978) did not note transient morphological featues, but the discrepancy between our results and those of Maslim et al. (1986) cannot be similarly explained. We believe that methodological differences may be responsible.

The technique of making intracellular dye injections of living ganglion cells under direct physiological control has several advantages over the method of extracellular HRP injection used by Maslim et al. (1986). One is that with intracellular injections it is possible to obtain more reliable and complete filling of the fine spines, filopodia, and axons-processes that may not have been filled to the same extent using the extracellular technique. Another advantage is that the physiological state of the retina can be monitored: since it is routine to record membrane resting potentials and even some synaptic activity, we believe that the retinas are maintained in a reasonably healthy state using the rapidly perfused, oxygenated tissue chamber. (It is worth noting that in a similar preparation fetal retinogeniculate synapses continue to function for up to $10 \mathrm{hr}$; see Shatz and Kirkwood, 1984.) Under the conditions of our experiments, injected immature ganglion cells are not only studded with fine processes, but their main dendrites do not have the beaded, varicose appearance that is frequently observed when a cell is damaged by excessive dye injection, fluorescence overillumination, or anoxia.

Our results show that cat retinal ganglion cell form is achieved by a combination of growth and remodeling of not only dendrites but also of axons, which have extra intraretinal collaterals and side branches during development but not in the adult. In the adult these processes must be exceedingly rare, if present at all, since in the many previous morphological studies of adult cat ganglion cells (e.g., Boycott and Wässle, 1974; Nelson et al., 1978; Rodieck, 1979; Saito, 1983; Fukuda et al., 1984) no such branches or collaterals have been seen, with the exception of Dacey (1985) who reported the existence of an intraretinal axonal bifurcation for one ganglion cell. To our knowledge, these transient morphological features also have not been reported in previous studies of cat retinal ganglion cells during development
(Rusoff and Dubin, 1978; Rusoff, 1979; Maslim et al., 1986; Dann et al., 1987, 1988). Again, the same methodological reasons considered above can account for the discrepancy in the developmental results. It is worth mentioning in this regard that Dann et al. $(1987,1988)$ used fixed retinae for their intracellular injections, and while the fixation may not have affected the ability to fill dendritic spines, it may have prevented the filling of axon side branches and collaterals. Thus, it may be csscntial to use living retinae and intracellular dye injections to resolve these fine axonal processes.

These observations of transient morphological features of ganglion cells during development in the cat may be extended to ganglion cell development in other mammalian species since excessive numbers of dendritic spines have also been reported during the postnatal development of the rat retina (Perry and Walker, 1980). The situation regarding axonal exuberance (e.g., the elimination of intraretinal collaterals and side branches seen in our study) is not as clear in other species, perhaps in part because the Golgi impregnation technique used by Perry and Walker (1980) may not have revealed sufficient axonal detail. In contrast, in lower vertebrates a transient exuberance in dendritic processes has not been observed, nor have intraretinal axon collaterals been reported. For example, recent studies of the morphological development of ganglion cells in the goldfish (Hitchcock and Easter, 1986) and in Xenopus (Sakaguchi et al., 1984) conclude that the final form of retinal ganglion cells is achieved principally by a process of constant dendritic growth, a conclusion supported in the goldfish study by a quantitative analysis of dendritic branching. While it is possible that methodological differences contribute to this conclusion, another altcrnative is that therc is a real species difference that might exist because, as discussed above, the time course and pattern of neurogenesis and retinal growth differ profoundly between mammals and lower vertebrates.

The remodeling of retinal ganglion cells seen here is another example among many known to occur during neuronal development in mammals. The transient exuberance of dendritic and somatic spines has been well-documented in the development of cerebral cortical neurons (e.g., Boothe et al., 1979) and Purkinje cells (Larramendi, 1969; Sotelo, 1982), but in comparison to retinal ganglion cells, the changes are modest in these cell types because many more spines are retained into adulthood. There are also several cases of dendritic remodeling, the most conclusive being the nucleus magnocellularis neurons in the chick that receive input from auditory nerve fibers (Jackson and Parks, 1982; Jhaveri and Morest, 1982). In the adult, these neurons have no dendrites, whereas in development they have many. While mammalian retinal ganglion cell dendrites do not undergo such a drastic change, our branch point analysis (Figs. $16,17)$ indicates that a definite decrease in dendritic complexity does occur.

In addition to dendritic remodeling, the results of our study have demonstrated that the intraretinal portions of ganglion cell axons also undergo substantial remodeling. While it is now well known that cerebral cortical neurons can send and then retract axon collaterals to several distant targets during development (for review, see Cowan et al., 1984), little is known about the intrinsic pattern of axon branching within the structure of origin, at least in the mammalian CNS. However, a recent study of the development of frog cardiac ganglion cells has shown that these neurons extend several axons within the ganglion during development but retain only one at maturity (Heathcote and Sar- 
Table 3. Developmental changes in axonal complexity of ganglion cells

\begin{tabular}{llll} 
Age & $n$ & $\begin{array}{l}\text { Axons with } \\
\text { bifurcations } \\
(\%)\end{array}$ & $\begin{array}{l}\text { Axons } \\
\text { with side } \\
\text { branches } \\
(\%)\end{array}$ \\
\hline E35 & 39 & 10 & 50 \\
E36 & 22 & 14 & 64 \\
E37 & 58 & 5 & 58 \\
E45 & 17 & 6 & 61 \\
E50/52 & 27 & 8 & 58 \\
E57 & 22 & 5 & 50 \\
E62/63 & 83 & 9 & 55 \\
P3 & 13 & 8 & 62 \\
P7/8 & 73 & 7 & 72 \\
P15 & 16 & 0 & 50 \\
P31/32 & 60 & 0 & 50 \\
Adult & 15 & 0 & 0 \\
\hline
\end{tabular}

gent, 1985). These comparisons with neuronal development in other species and systems suggest that the extent of remodeling undergone by mammalian retinal ganglion cells is somewhere in the middle of a continuum exemplified at one extreme by the complete loss of dendrites and the retraction of many intrinsic axons, and at the other extreme by continuous interstitial growth without remodeling.

\section{Role of transient processes during ganglion cell development}

In thinking about the possible roles played by the transient processes seen on retinal ganglion cell somata, dendrites, and intraretinal axons, it is useful to examine the time course of appearance and disappearance of these morphological features in relation to other developmental events known to occur either within the retina or within its central targets. One possibility is that the presence of at least some of these transient processes within the retina is correlated directly with the remodeling of ganglion cell axon terminals known to occur within target structures during development. For example, previous studies have shown that between E45 and birth the eye-specific layers form in the cat's LGN as ganglion cell axons from the 2 eyes segregate from each other (Shatz, 1983; Sretavan and Shatz, 1986). Recent experiments have suggested that this process of segregation is likely to depend on ganglion cell action potential activity (Shatz and Kirkwood, 1984; Shatz and Stryker, 1988; Sretavan et al., 1987; see also Constantine-Paton and Reh, 1985), and if so, then one requirement is that the activity of neighboring ganglion cells within each retina must be correlated in order to preserve these neighbor relations within the target (Willshaw and von der Malsberg, 1976). Such correlations could be achieved in a number of ways. In the adult cat retina, Mastronarde (1983) has shown that nearby ganglion cells receive common presynaptic inputs, but this may not be the case during development, particularly early in prenatal life. However, our finding that throughout fetal and early neonatal life well over $50 \%$ of ganglion cell axons have side branches (Table 3) raises the possibility that such processes (and perhaps even the few intraretinal axon collaterals) may function to correlate activity locally within the retina by contacting neighboring ganglion cells either directly or via interneurons. If so, such processes should be presynaptic
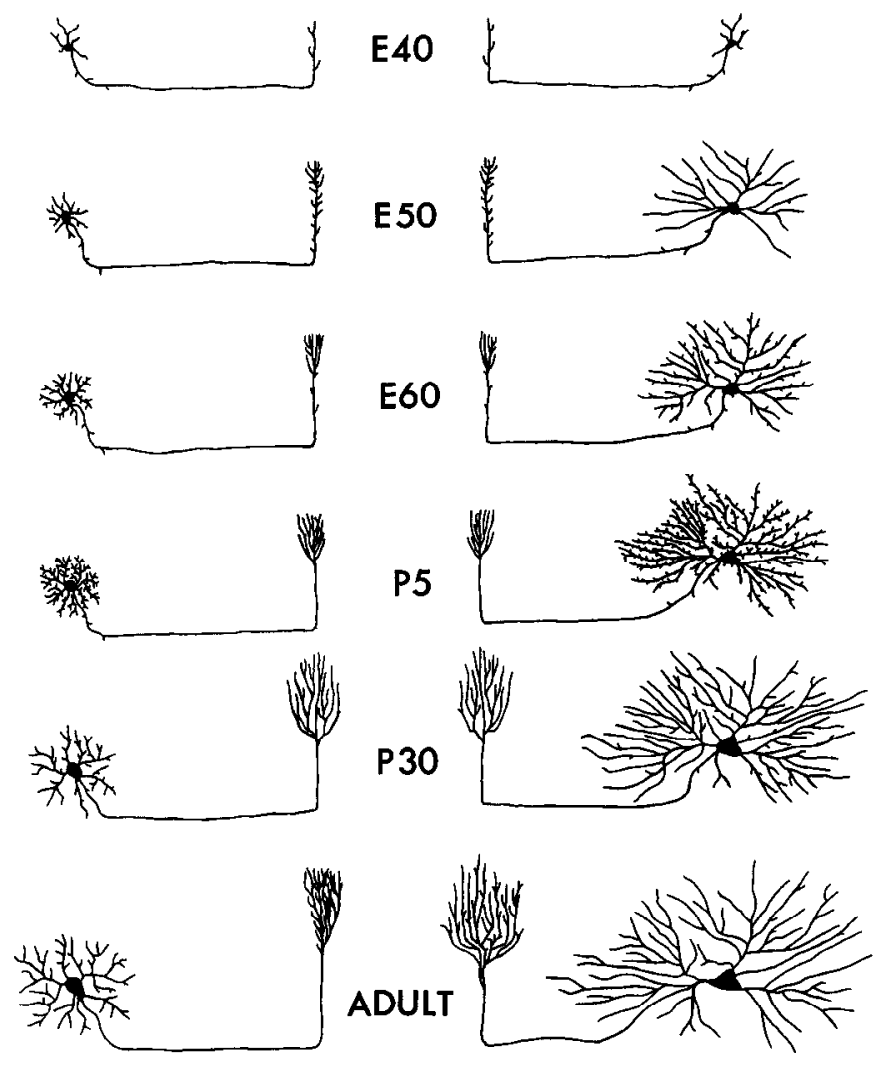

\section{BETA CELL}

ALPHA CELL

Figure 21. Schematic drawing illustrating the proposed stages of morphological development of a typical beta and alpha retinal ganglion cell (not to scale). Included is the entire cell from the soma within the retina to the axon terminations in the LGN (possible collaterals to the midbrain have been omitted). This figure illustrates that (1) the acquisition of class-specific dendritic morphology occurs many weeks before the terminal arbors belonging to different ganglion cell classes can be distinguished from each other and (2) that the period during which remodeling of ganglion cells occurs within the retina (E60-P30) is not correlated with the periods in which their axon terminals are being remodeled within the LGN (E40-60, P30-adult). See text for further details. Retinogeniculate axon arbor data are from the studies of Sretavan and Shatz (1986) for the ages E40 and 60; Mason (1982) for P5; Sur et al. (1984) for P30 to adult; and Bowling and Michael (1984) for the adult.

at the ultrastructural level, a suggestion that seems reasonable from the finding that the transient side branches along similar ganglion cell axons within the developing LGN can be presynaptic nerve terminals (Campbell and Shatz, 1986). Alternatively, ganglion cells might be directly coupled to each other by gap junctions, but this seems less likely in view of our observations that few ganglion cells are dye-coupled during the period of segregation of ganglion cell axons from the 2 eyes within the LGN.

In contrast, the time course of appearance and disappearance of the exuberant dendritic processes suggests that they may have different developmental significance. This time course is shown in Figure 21, a diagram illustrating the developmental history, both within the retina and LGN, of a representative alpha and a beta cell based on the results of experiments on prenatal (Sretavan and Shatz, 1986; Ramoa et al., 1987; present study) and postnatal (Bowling and Michael, 1984; Sur et al., 1984; Dann 
et al., 1987, 1988; Ramoa et al., 1987; present study) development of ganglion cells. As shown in Figure 21, between E40 and 60 the dendrites of ganglion cells begin to increase steadily in complexity as regards both dendritic branch points and spines, an increase that does not reach a maximum until about P5 (cf. Figs. 15-17). The basic framework of ganglion cell form is also laid down at this time, so that ganglion cells belonging to different morphological classes can be distinguished as early as E50 (cf. Fig. 21: E40 60). In contrast, morphological studies of individual retinogeniculate axons during this same period (Sretavan and Shatz, 1986) have shown that axon arbors resemble one another regardless of their class identity. When axons first grow into the LGN (between E30 and 40), they are simple (see Fig. 21, top). Then, during the period in which the eye-specific layers are forming, E45-60 (Shatz, 1983), ganglion cell axons elaborate their terminal arbors and are also studded with short side branches along their length within the LGN. By birth, when ganglion cell axon terminals from the 2 eyes have segregated from each other to form the eye-specific layers, the side branches have disappeared. This comparison of the changes undergone by axon terminals and dendrites indicates that during the period in which ganglion cell axons within the LGN are remodeled by elaborating and then losing their side branches, the dendrites of ganglion cells are growing steadily in size and complexity.

It is not until postnatal life that the dendrites of ganglion cells undergo extensive remodeling (Ramoa et al., 1987; Dann et al., 1987, 1988; present study). This occurs during the first 4 postnatal weeks, as shown for alpha and beta cells (Fig. 21), both of which lose large numbers of spines and considerably simplify their dendritic trees until about $\mathbf{P} 30$, when adultlike dendritic form is achieved. In contrast, during this same period the axon terminal arbors of ganglion cells grow extensively within the layers of the LGN appropriate to their eye of origin (see Shatz and Sretavan, 1986, Fig. 3). Finally, the remodeling of arbors that ultimately gives rise to the different adult patterns of alpha (Y) and beta (X) ganglion cell terminations within the LGN only begins after P30 (Sur et al., 1984), whereas from this time until adulthood the dendrites and somata of ganglion cells, particularly of those in peripheral retina, simply grow without further remodeling (present study; Dann et al., 1988). Therefore, the acquisition of class-specific dendritic morphology occurs many weeks before the terminal arbors belonging to different ganglion cell classes can be distinguished from each other either morphologically or physiologically.

The developmental sequence of morphological changes occurring to the axons and dendrites of ganglion cells can therefore be thought of as occurring in 3 stages. The first, between E40 and 60 , is characterized by the growth and remodeling of ganglion cell axon terminals as they segregate to form the eyespecific layers within the LGN and the progressive growth of dendrites within the retina. The second, between E60 and P30, is characterized by the simple growth of ganglion cell axon terminals and the growth and extensive remodeling of dendrites. The third stage, from P30 to adult, is characterized by the final remodeling of axon terminals and the simple growth of somata and dendrites. Thus, it would seem that the period during which remodeling of ganglion cells occurs within the retina is not at all correlated with the periods in which their terminals are being remodeled within the LGN. These observations suggest that the role of the exuberant dendritic and somatic processes is related to events occurring within the retina rather than to those occurring within the target.
One major event that occurs within the retina during development is the massive elimination of ganglion cells due to cell death (for review, see Shatz and Sretavan, 1986). In the cat, counts of the number of axons in the optic nerve at different times during development indicated that roughly $70 \%$ of all ganglion cells are lost and that the major wave of ganglion cell death occurs between about E40 and 60 (Williams et al., 1986). However, this period is well before the peak and ensuing decline in dendritic exuberance. Thus, while cell death could in some way signal the onset of spine production, it is very unlikely to regulate the remodeling of the entire dendritic arbor.

During the period in which dendritic and somatic spines appear and disappear, synaptogenesis is taking place in the inner plexiform layer. Ultrastructural studies of synapse formation in the cat retina have indicated that as early as E45 conventional synapses are seen within the future inner plexiform layer; however, at this time the synapses are presumed to be between amacrine cell processes (Maslim and Stone, 1986). The first conventional synapses thought to be formed between amacrine cells and ganglion cells are found at about E56, whereas the first ribbon synapses signaling the formation of bipolar to ganglion cell contacts are not seen until birth (Cragg, 1975; Maslim and Stone, 1986), and these appear to increase to approximate adult levels by about 3 weeks after birth (Morrison, 1982). Therefore, the entire period of ganglion cell dendritic exuberance and remodeling occurs during the period of synaptogenesis within the inner plexiform layer, with the period of increased dendritic complexity occurring largely during the formation of conventional synapses and the period of declining complexity (remodeling) occurring with the formation of ribbon synapses. These considerations suggest that the spines themselves may be directly involved in the events of synaptogenesis, perhaps as the sites of transient synapses. While there is no direct evidence for this suggestion in the cat retina, recent ultrastructural studies of synaptogenesis in primate retina are consistent with the presence of synapses onto small dendritic protrusions (Nishimura and Rakic, 1987). In other developing systems such as the cerebellum, it is known that synapses are formed onto the transient somatic spines of Purkinje cells (Larramendi, 1969), making it reasonable that similar contacts are present on the somatic (and even the dendritic) spines of retinal ganglion cells.

Finally, it is worth noting that the period of ganglion cell remodeling occurring between $\mathrm{P} 5$ and 30 , during which there is a decline in the number of spines and branch points, coincides well with the sensitive period in which cat ganglion cell dendrites can respond to the effects of manipulations that alter their neighbor relationships (Eysel et al., 1985). During this sensitive period, lesions that delete some ganglion cells result in the redirection of the dendritic tree of remaining ganglion cells into the lesioned area, an observation consistent with the idea originally proposed by Perry and Linden (1982; see also Wässle et al., 1981; Kirby and Chalupa, 1986) that during normal development some form of dendritic competition for presynaptic inputs controls the dendritic territory of ganglion cells. If, as seems likely, synaptic contacts are made onto the transient dendritic and somatic spines of ganglion cells, then these exuberant processes may represent the morphological substrate for dendritic competition within the retina.

\section{References}

Boothe, R. D., W. T. Greenough, J. S. Lund, and K. Wrege (1979) A quantitative investigation of spine and dendrite development of neu- 
rons in visual cortex (area 17) of Macaca nemestrina monkeys. J. Comp. Neurol. 186: 473-490.

Bowling, D. R., and C. R. Michael (1984) Terminal patterns of single, physiologically characterized optic trait fibers in the cat's lateral geniculate nucleus. J. Neurosci. 4: 198-216.

Boycott, B. B., and H. Wässle (1974) The morphological types of ganglion cells of the domestic cat's retina. J. Physiol. (Lond.) 240: $397-420$.

Brening, R. K., and R. W. Rodieck (1986) Morphology of the cat ganglion cells that project to the superior colliculus. Invest. Ophthalmol. Vis. Sci. Suppl. 27: 223.

Campbell, G., and C. J. Shatz (1986) Synapses formed by individual retinogeniculate axons in inappropriate LGN territory during prenatal development of the cat's retinogeniculate projection. Soc. Neurosci. Abstr. 12: 589 .

Campbell, G., A. S. Ramoa, and C. J. Shatz (1987) Do amacrine cells extend, then retract, a centrally-projecting axon? Soc. Neurosci. Abstr. 13: 589 .

Constantine-Paton, M., and T. A. Reh (1985) Dynamic synaptic interactions during the formation of a retinotopic map. In Neurobiology: Molecular Biological Approaches to Understanding Neuronal Function and Development, P. O'Lague, ed., pp. 151-168, Liss, New York.

Cowan, W. M., J. W. Fawcett, D. D. M. O'Leary, and B. B. Stanfield (1984) Regressive events in neurogenesis. Science 225: 1258-1265.

Cragg, B. G. (1975) The development of synapses in the visual system of the cat. J. Comp. Neurol. 160: 147-166.

Dacey, D. M. (1985) Wide-spreading terminal axons in the inner plexiform layer of the cat's retina: Evidence for intrinsic axon collaterals of ganglion cells. J. Comp. Neurol. 242: 247-262.

Dann, J. F., E. H. Buhl, and L. Peichl (1987) Dendritic maturation in cat retinal ganglion cells: A Lucifer Yellow study. Neurosci. Lett. 80: 21-26.

Dann, J. F., E. H. Buhl, and L. Peichl (1988) Postnatal dendritic maturation of alpha and beta ganglion cells in cat retina. J. Neurosci. 8: 1485-1499.

Eysel, U., L. Peichl, and H. Wässle (1985) Dendritic plasticity in the early postnatal feline retina: Quantitative characteristics and sensitive period. J. Comp. Neurol. 242: 134-145.

Friedlander, M. J., K. A. C. Martin, and C. Vahle-Hinz (1985) The structure of the terminal arborizations of physiologically identified retinal ganglion cell Y-axons in the kitten. J. Physiol. (Lond.) 359: 293-314.

Fukuda, Y., C. Hsiao, M. Watanabe, and H. Ito (1984) Morphological correlates of physiologically identified $\mathrm{Y}-, \mathrm{X}$-, and W-cells in the cat retina. J. Neurophysiol. 52: 999-1013.

Heathcote, R. D., and P. B. Sargent (1985) Loss of supernumerary axons during neuronal morphogenesis. J. Neurosci. 5: 1940-1946.

Hitchcock, P. F., and S. S. Easter, Jr. (1986) Retinal ganglion cells in goldfish: A qualitative classification into four morphological types, and quantitative study of the development of one of them. J. Neurosci. 6: $1037-1050$.

Hudspeth, A. J., and D. P. Corey (1978) Controlled bending of highresistance glass micropipettes. Am. J. Physiol. 234: C56-C57.

Jackson, H., and T. N. Parks (1982) Functional synapse elimination in the developing avian cochlear nucleus with simultaneous reduction in cochlear nerve branching. J. Neurosci. 2: 1736-1743.

Jacobs, D. S., V. H. Perry, and M. J. Hawken (1984) The postnatal reduction of the uncrossed projection from the nasal retina in the cat. J. Neurosci. 4: 2425-2433.

Jhaveri, S., and D. K. Morest (1982) Sequential alterations of neuronal architecture in nucleus magnocellularis of the developing chicken: $A$ Golgi study. Neuroscience 7: 837-853.

Johns, P. R., and S. S. Easter, Jr. (1977) Growth of the adult goldfish eye. III. Increase in retinal cell number. J. Comp. Neurol. 176: 331342.

Johns, P. R., A. C. Rusoff, and M. W. Dubin (1979) Postnatal neurogenesis in the kitten retina. J. Comp. Neurol. 187: 545-556.

Katz, L. C. (1987) Local circuitry of identified projection neurons in cat visual cortex brain slices. J. Neurosci. 7: 1223-1249.

Katz, L. C., A. Burkhalter, and W. J. Dreyer (1984) Fluorescent latex microspheres as a retrograde neuronal marker for in vivo and in vitro studies of visual cortex. Nature 310:498-500.

Kirby, M. A., and L. M. Chalupa (1986) Retinal crowding alters the morphology of alpha ganglion cells. J. Comp. Neurol. 251: 532-541.

Kliot, M., and C. J. Shatz (1982) Genesis of different retinal ganglion cell types in the cat. Soc. Neurosci. Abstr. 8: 815.
Kolb, H., R. Nelson, and A. Mariani (1981) Amacrine cells, bipolar cells and ganglion cells of the cat retina: A Golgi study. Vision Res. 21: $1081-1114$.

Larramendi, L. M. H. (1969) Analysis of synaptogenesis in the cerebellum of the mouse. In Neurobiology of Cerebellar Evolution and Development, R. Llinás, ed., pp. 804-843, American Medical Association, Chicago.

Leventhal, A. G., J. Keens, and I. Tork (1980) The afferent ganglion cells and cortical projections of the retinal recipient zone (RRZ) of the cat's "pulvinar complex." J. Comp. Neurol. 194: 535-554.

Leventhal, A. G., R. W. Rodieck, and B. Dreher (1985) Central projections of cat retinal ganglion cells. J. Comp. Neurol. 237: 216-226.

Lia, B., R. W. Williams, and L. M. Chalupa (1983) Early development of retinal specialization: The distribution and decussation patterns of ganglion cells in the prenatal cat demonstrated by retrograde peroxidase labeling. Soc. Neurosci. Abstr. 9: 702.

Lia, B., R. W. Williams, and L. M. Chalupa (1987) Formation of retinal ganglion cell topography during prenatal development. Science 236: 848-851.

Maslim, J., and J. Stone (1986) Synaptogenesis in the retina of the cat. Brain Res. 373: 35-48.

Maslim, J., M. Webster, and J. Stone (1986) Stages in the structural differentiation of retinal ganglion cells. J. Comp. Neurol. 254: 383402.

Mason, C. A. (1982) Development of terminal arbors of retino-geniculate axons in the kitten. I. Light microscopical observations. Neuroscience 7: $541-559$.

Mastronarde, D. N. (1983) Correlated firing of cat retinal ganglion cells. I. Spontaneously active inputs to X-and Y-cells. J. Neurophysiol. 49: 303-324.

Mastronarde, D. N., M. A. Thibeault, and M. W. Dubin (1984) Nonuniform postnatal growth of the cat retina. I. Comp. Neurol. 228: 598-608.

Morrison, J. D. (1982) Postnatal development of the area centralis of the kitten retina: An electron microscopic study. J. Anat. 135: 255271.

Nelson, R., E. V. Famiglietti, and H. Kolb (1978) Intracellular staining reveals different levels of stratification for $\mathrm{ON}$ - and OFF-centre cells in cat retina. J. Neurophysiol. 41: 472-483.

Nishimura, Y., and P. Rakic (1987) Development of the rhesus monkey retina: II. A three-dimensional analysis of the sequences of synaptic combinations in the inner plexiform layer. J. Comp. Neurol. 262: 290-313.

Peichl, L., and H. Wässle (1981) Morphological identification of onand off-centre brisk transient $(\mathrm{Y})$ cells in the cat retina. Proc. R. Soc. London [Biol.] 212: 139-156.

Perry, V. H., and R. Linden (1982) Evidence for dendritic competition in the developing retina. Nature 297: 683-685.

Perry, V. H., and M. Walker (1980) Morphology of cells in the ganglion cell layer during development of the rat retina. Proc. R. Soc. London [Biol.] 208: 433-445.

Ramoa, A. S., G. Campbell and C. J. Shatz (1987) Transient morphological features of identified ganglion cells in living fetal and neonatal retina. Science 237: 522-525.

Rapaport, D. H., and J. Stone (1982) The site of commencement of maturation in mammalian retina: Observations in the cat. Dev. Brain Res. 5: 273-279.

Rapaport, D. H., and J. Stone (1983) Time course of the morphological differentiation of cat retinal ganglion cells: Influences on cell size. J. Comp. Neurol. 221: 42-52.

Robinson, S. R. (1987) Ontogeny of the area centralis in the cat. J. Comp. Neurol. 255: 50-67.

Rodieck, R. W. (1979) Visual pathways. Annu. Rev. Neurosci. 2: 193225.

Rodieck, R. W., and R. K. Brening (1983) Retinal ganglion cells: Properties, types, genera, pathways and trans-species comparisons. Brain Behav. Evol, 23: 121-164.

Rusoff, A. C. (1979) Development of ganglion cells in the retina of the cat. In Developmental Neurobiology of Vision, R. Freeman, ed., pp. 19-30, Plenum, New York.

Rusoff, A. C., and M. W. Dubin (1977) Development of receptivefield properties of retinal ganglion cells in kittens. J. Neurophysiol. 40: 1188-1198.

Rusoff, A. C., and M. W. Dubin (1978) Kitten ganglion cells: Dendritic field size at 3 weeks of age and correlation with receptive field size. Invest. Ophthalmol. Vis. Sci. 17: 819-821. 
Saito, H. A. (1983) Morphology of physiologically identified X-, Yand W-type retinal ganglion cells of the cat. J. Comp. Neurol. 221. 279-288.

Sakaguchi, D. S., R. K. Murphey, R. K. Hunt, and R. Tompkins (1984) The development of retinal ganglion cells in a tetraploid strain of Xenopus laevis: A morphological study utilizing intracellular dye injection. J. Comp. Neurol. 224: 231-251.

Scott, P. P. (1970) Cats. In Reproduction and Breeding Techniques for Laboratory Animals, E. S. E. Hafez, ed., pp. 192-208, Lea \& Febiger, Philadelphia.

Shatz, C. J. (1983) The prenatal development of the cat's retinogeniculate pathway. J. Neurosci. 3: 482-499.

Shatz, C. J., and P. A. Kirkwood (1984) Prenatal development of functional connections in the cat's retinogeniculate pathway. J. Neurosci. 4: 1378-1397.

Shatz, C. J., and D. W. Sretavan (1986) Interactions between retinal ganglion cells during the development of the mammalian visual system. Annu. Rev. Neurosci. 9: 171-207.

Shatz, C. J., and M. P. Stryker (1988) Prenatal tetrodotoxin infusion blocks segregation of retinogeniculate afferents. Science (in press).

Sherman, S. M. (1985) Development of retinal projections to the cat's lateral geniculate nucleus. Trends Neurosci. 8: 350-355.

Sotelo, C. (1982) Synaptic remodelling in agranular cerebellum. In The Cerebellum-New Vistas, S. L. Palay and V. Chan-Palay, eds., pp. 50-68, Springer-Verlag, New York.

Sretavan, D. W., and C. J. Shatz (1986) Prenatal development of retinal ganglion cell axons: Segregation into eye-specific layers within the cats lateral geniculate nucleus. J. Neurosci. 6: 234-251.

Sretavan, D. W., C. J. Shatz, and M. P. Stryker (1987) Prenatal development of retinogeniculate axon arbors in the presence of tetrodotoxin. Soc. Neurosci Abstr. 13: 591 .

Stanford, L. R. (1987) W-cells in the cat retina: Correlated morphological and physiological evidence for two distinct classes. J. Neurophysiol. 57: 218-244.
Stewart, W. W. (1978) Functional connections between cells as revealed by dye-coupling with a highly fluorescent Naphthalimide tracer. Cell 14: 741-759.

Stone, J. (1981) The Whole Mount Handbook, Maitland Publications, Sydney.

Sur, M., R. E. Weller, and S. M. Sherman (1984) Development of Xand $Y$-cell retinogeniculate terminations in kittens. Nature 310:246249.

Walsh, C., and E. H. Polley (1985) The topography of ganglion cell production in the cat's retina. J. Neurosci. 5: 741-750.

Walsh, C., E. H. Polley, T. L. Hickey, and R. W. Guillery (1983) Generation of cat retinal ganglion cells in relation to central pathways. Nature 302: 611-614.

Wässle, H. (1982) Morphological typcs and central projections of ganglion cells in the cat retina. In Progress in Retinal Research, N. Osborne and G. Chandler, eds., pp. 125-152, Pergamon, Oxford.

Wässle, H., W. R. Levick, and B. G. Cleland (1975) The distribution of the alpha type of ganglion cells in the cat's retina. J. Comp. Neurol. 159: 419-438.

Wässle, H., L. Peichl, and B. B. Boycott (1981) Dendritic territories of cat retinal ganglion cells. Nature 292: 344-345.

Williams, R. W., and L. M. Chalupa (1982) Prenatal development of retinocollicular projections in the cat: An anterograde tracer transport study. J. Neurosci. 2: 604-622.

Williams, R. W., M. J. Bastiani, B. Lia, and L. M. Chalupa (1986) Growth cones, dying axons, and developmental fluctuations in the fiber population of the cat's optic nerve. J. Comp. Neurol. 246: 32 69.

Willshaw, D. J., and C. von der Malsberg (1976) How patterned neural connections can be set up by self-organization. Proc. R. Soc. London [Biol.] 194: 431-445. 